\title{
On the development of the chondrocranium and the histological anatomy of the head in perinatal stages of marsupial mammals
}

\author{
Marcelo R. Sánchez-Villagra ${ }^{*}$ and Analía M. Forasiepi ${ }^{2}$
}

\begin{abstract}
An overview of the literature on the chondrocranium of marsupial mammals reveals a relative conservatism in shape and structures. We document the histological cranial anatomy of individuals representing Monodelphis domestica, Dromiciops gliroides, Perameles sp. and Macropus eugenii. The marsupial chondrocranium is generally characterized by the great breadth of the lamina basalis, absence of pila metoptica and large otic capsules. Its most anterior portion (cupula nasi anterior) is robust, and anterior to it there are well-developed tactile sensory structures, functionally important in the neonate. Investigations of ossification centers at and around the nasal septum are needed to trace the presence of certain bones (e.g., mesethmoid, parasphenoid) across marsupial taxa. In many adult marsupials, the tympanic floor is formed by at least three bones: alisphenoid (alisphenoid tympanic process), ectotympanic and petrosal (rostral and caudal tympanic processes); the squamosal also contributes in some diprotodontians. The presence of an entotympanic in marsupials has not been convincingly demonstrated. The tubal element surrounding the auditory tube in most marsupials is fibrous connective tissue rather than cartilage; the latter is the case in most placentals recorded to date. However, we detected fibrocartilage in a late juvenile of Dromiciops, and a similar tissue has been reported for Tarsipes. Contradictory reports on the presence of the tegmen tympani can be found in the literature. We describe a small tegmen tympani in Macropus. Several heterochronic shifts in the timing of development of the chondocranium and associated structures (e.g., nerves, muscles) and in the ossification sequence have been interpreted as largely being influenced by functional requirements related to the altriciality of the newborn marsupial during early postnatal life. Comparative studies of chondocranial development of mammals can benefit from a solid phylogenetic framework, research on non-classical model organisms, and integration with imaging and sectional data derived from computer-tomography.
\end{abstract}

Keywords: Ontogeny, Skull, Tegmen tympani, Auditory bulla, Entotympanic, Tubal element, Dromiciops, Monodelphis, Macropus, Perameles

“...in morphology general principles are founded on matters of quite intricate detail and require detail for their illustration."

De Beer [1], page xxix.

\section{Background}

The study of comparative anatomy has been dramatically enhanced in the last decades by the availability of three-

\footnotetext{
* Correspondence: m.sanchez@pim.uzh.ch

${ }^{1}$ Paläontologisches Institut und Museum der Universität Zürich, Karl Schmid

Strasse 4, Zürich 8006, Switzerland

Full list of author information is available at the end of the article
}

dimensional, non-invasive imaging made possible by computed tomography (hereafter, CT scanning) [2-4]. Scanning offers a means to acquire high-quality information from areas of the skull that would otherwise be unavailable except via invasive techniques.

Studies based on CT scanning involve the documentation of sections, analogous to histological work. In this regard, CT scanning is a very helpful guide, permitting quick identification of structures and the reconstruction of soft-tissues without the effort needed to produce wellprocesed and stained serial sections [5]. High-resolution CT scanning, together with new methods of staining, have been used to generate three-dimensional images of organs and soft tissues, which could potentially have a 
significant impact on studies of organogenesis and anatomy [6, 7]. However, the precise level of anatomical resolution which may be attained by histological serial sectioning cannot yet be matched by CT scanning. Thanks to color differentiation, serial sections can provide detailed information about cartilage, membranes, relationships of blood vessels and nerves, and different tissues and organs, in some cases leading to the discovery of cladistically diagnostic features [8-12]. Histological serial sections can also provide information on the nature of the tissues, giving insights into their origin, development and distribution of mechanical strain [13].

The objective of this contribution is to provide a reference on the sectional anatomy of the developing marsupial head, summarize major features of the anatomy of the marsupial chondrocranium, and discuss some controversial issues concerning the ethmoidal, orbitotemporal and basicranial regions. We document species that represent several major groups of extant marsupials, including Didelphimorphia, Microbiotheria, Peramelemorphia and Diprotodontia (Fig. 1).

\section{Marsupial evolution, cranial anatomy and development}

Marsupialia is the crown group that includes the common ancestor of all extant marsupials and their descendants. Metatheria is the most inclusive group of mammals more closely related to opossums and their fossil relatives than to placentals [14]. Metatheria encompasses stem marsupials going back to perhaps Jurassic times [15].

Traditionally, marsupials, in particular opossums (didelphids), have been taken as models to investigate early mammalian evolution [16-19]. Several plesiomorphic features retained in the musculoskeletal system resulted in the interpretation of opossums as models for understanding the therian last common ancestor. However, this does not imply that their anatomy is lacking in complexity [20]. Monodelphis is a didelphid of growing importance in biomedical research, and one that has been used in evolutionary studies of mammalian development [21-23]. Dromiciops is a key taxon to understand issues within marsupial phylogeny, representing a member of an otherwise Australasian clade (Fig. 1).

Several aspects of the adult cranial anatomy of marsupials have been treated since the late 19th century (e.g., $[9,17,24-37])$. These works are based mostly on the macroscopic examination of macerated skulls, including that of Wible [30] on the skull of Monodelphis brevicaudata, which clarifies terminological issues and establishes a clear reference to didelphid adult anatomy (see also [38]).

The architecture of the embryonic marsupial cranium has been interpreted as largely influenced by functional requirements related to a particular mode of reproduction [39]. It is assumed that the cranium of the altricial newborn marsupial must be able to withstand the mechanical strain of sucking at the teat, from which it is suspended within the marsupium [40-43]. Heterochronic shifts have been detected towards the extreme precocity of ossification of the bones of the snout (e.g. premaxilla, maxilla, palatine, dentary), particularly the palate [1] and the back of the skull (e.g., exoccipital) [44] to support active suckling. With respect to the chondrocranium, comparisons with monotremes, which do not suckle at birth, are needed $[12,45]$ as to establish the polarity of many traits and test some of the claims on a novel functional significance for several marsupial traits.

The chondrocranium consists of numerous individual chondrification centers that appear at different times and fuse, forming a single structure that forms the earliest phase of the developing fetal skull. Most of the chondrocranium is replaced by ossifications; however, some parts become resorbed in later ontogenetic stages while others persist into the adult stage (e.g., nasal cartilages). The skull has different ossification modes; it is completed via direct (intramembranous) and indirect (perichondral and endochondral) osteogenesis. These processes operating in the formation of the different kinds of bones and their histology, ontogenetic and phylogenetic history, have been discussed comprehensively by Hall [13] and Padian and Lamm [46]. Intramembranous osteogenesis, also called periosteal or subperiosteal osteogenesis [13], represents the conversion of a fibrous mesenchymal precursor directly into bone, the result of which is usually called "dermal" bone. Perichondral and endochondral osteogenesis require an intermediate cartilaginous precursor before bone deposition. This sequence produces endochondral bones, also called "replacement" bones. Appositional bone ("Zuwachsknochen") does not have a cartilaginous precursor [47] and thus resembles dermal bone, although it grows by apposition on a cartilaginous core.

\section{Developing head anatomy - the chondrocranium}

Much of the literature on cranial marsupial development is from the first part of the 20th century. What makes it somewhat difficult to access is not so much the fact that most of it was published in German, but rather that it is highly descriptive in nature, without what we would understand today as a clear phylogenetic underpinning, and with a plethora of terms that tend to describe single or only a few stages. In what follows, our descriptions suffer from these two limitations by necessity. In most cases the kind of information necessary for explicit analytical quantification of character evolution is entirely missing (e.g., [48]).

Broom [49-52] studied several aspects of the marsupial chondrocranium. There are also detailed studies on the common opossum Didelphis marsupialis 


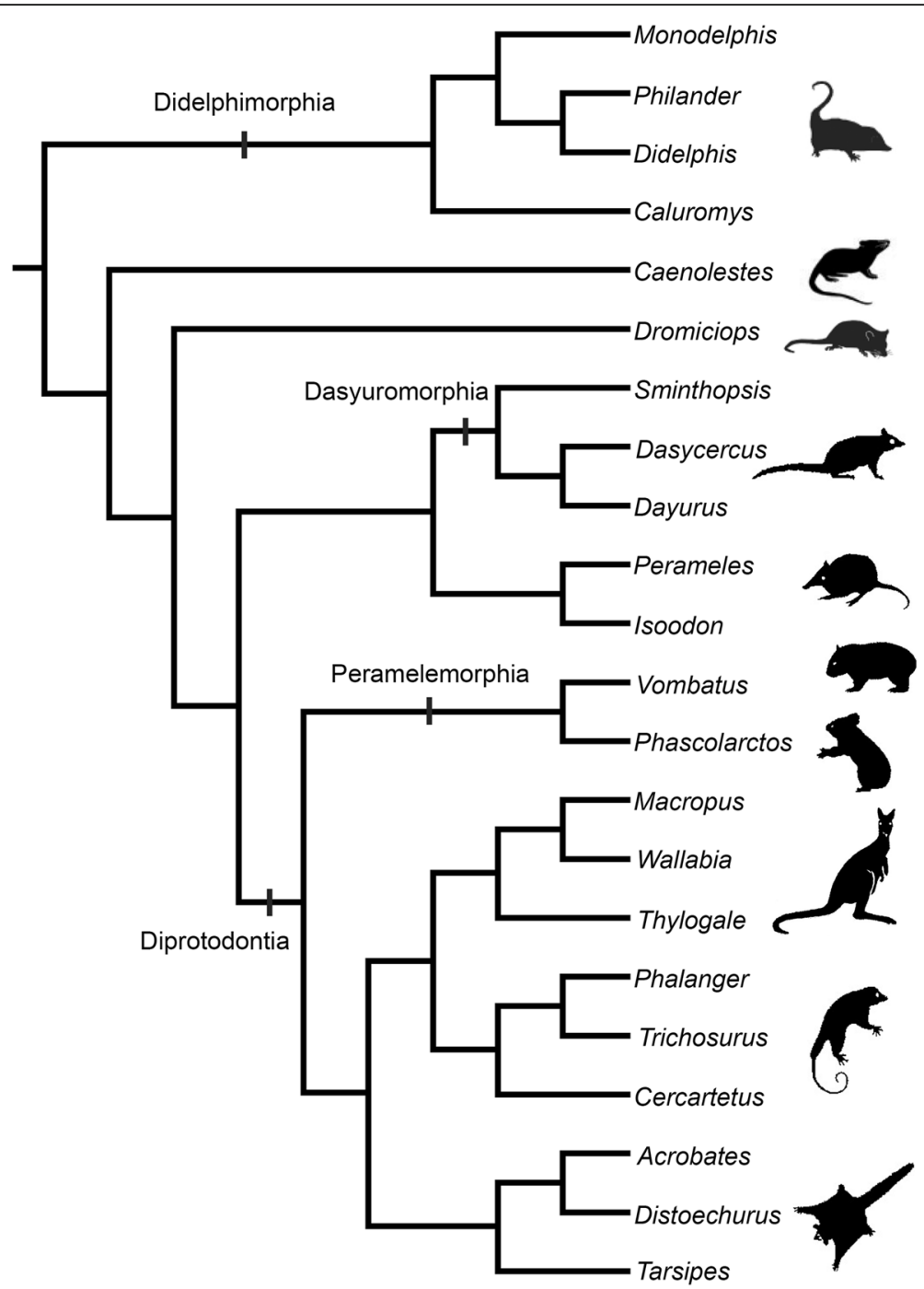

Fig. 1 Phylogeny of main species discussed in the text, representatives of several major groups of extant marsupials, including Didelphimorphia, Microbiotheria, Peramelemorphia and Diprotodontia. Phylogeny of diprotodontians is after Meredith et al. [211], of dasyuromorphians is after Westerman et al. [212]; major relationships among groups based on Gallus et al. [213] and Beck et al. [214]. Animal outlines modified from Horovitz and Sánchez-Villagra [102] and from Gallus et al. [213]

by Toeplitz [53], the bare-tailed woolly opossum Caluromys philander by Denison and Terry [54], the eastern quoll Dasyurus viverrinus by Broom [51], and the long-nosed and the short nose bandicoot Perameles nasuta and P. obesula by Cords [55] and Esdaile [56], respectively. Maier presented a series of contributions [31, 41, 42, 57-59] richly informative on the short-tailed opossum Monodelphis domestica and other marsupials. Several of his students at the Universities of Tübingen and Frankfurt wrote theses on other species, including Klutzny [60] on the wombat Vombatus ursinus, Müller [61] on the swamp wallaby Wallabia rufogrisea, and Schmelzle [62] on the tammar wallaby Macropus eugenii. Clark and Smith [63] and Smith [64] presented a great deal of documentation on the histological cranial anatomy of Monodelphis domestica and Macropus eugenii.

In this contribution, much of the data on developmental cranial anatomy presented in the doctoral thesis of Sánchez-Villagra [65] are presented for the first time. The doctoral dissertations of Wible [9] and of Aplin [66] are major contributions to the subject. The information on marsupials in Wible [9] contains copious unpublished details, which add to his many contributions on cranial anatomy [67, 68]. The doctoral thesis of Aplin [66] includes thorough documentation, description and comparisons of the basicranial region of diprotodontian marsupials in which many taxa are examined for this first time with histological series. 
Comparisons with marsupials have been made in studies on the chondrocranium and osteocranial development of placentals (e.g., $[8,69-71]$ ) and monotremes [45, 72]; see overviews in de Beer [1] and Moore [73], and general revisions on ontogeny illustrated under a broad phylogenetic context [74].

The temporal window of development examined in this paper is one that can be best described as "perinatal", meaning the time around birth. This is a critical time in organogenesis [75], traditionally omitted by embryologists concerned with earlier stages of development (e.g., [76-78]), or by those interested in growth, for which a morphometric study of postnatal stages is usually applied (e.g., [79, 80]). These boundaries are increasingly overstepped by studies that examine growth trajectories across much of ontogeny [81-83], or by those concerned with organogenesis and sequence in development [84]. As stated by Maier ([75]:60) regarding data on perinatal stages, these "not only narrow an existing gap of morphological knowledge, but they refer to a phase of life which is very peculiar and specialized in mammalian life history". Given the wide range of altricial to precocial development at birth [85], the latter is not a reliable stage of comparison across mammals, so the term "perinatal" is used here in a broad sense.

It is important to consider the timeframe in which the chondrocranium, the focus of much of this work, is formed, but has not yet begun to differentiate into bone. That stage is one that has been called the "critical period" or stadium optimum. In the context of a description of two marsupial embryos, Beard [86] stated: "The 'critical period' in a morphological sense is that epoch of the development when all the parts of the organism are first present as the foundations or 'Anlagen' of all the organs; it is that state when epigenesis is ended, and evolution or unfolding is beginning; it is that point where the individuality of the organism is first attained, when it has acquired a something setting it down as the embryo of some particular form, and when it is first beginning to resemble its progenitors". In reality, the difficulty in comparative studies of the chondrocranium lies in the fact that there is no objective way to identify comparable stages $[87,88]$. A series including several stages is thus desirable, but acquiring the necessary specimens is time-consuming. That is why some authors have followed the strategy of focusing on regions of the chondrocranium for extensive comparisons including developmental series of different species $[48,89$, 90]. The perinatal time is arguably the most important period for understanding critical aspects of the developmental anatomy of the mammalian skull and the homology of its various components $[8,71,91]$.

\section{Materials and methods}

Figures 2, 3, 4, 5, 6, 7, 8, 9, 10, 11, 12, 13, 14, 15 and 16 illustrate the histological cranial anatomy of individuals representing four species: Monodelphis domestica postnatal day (PND) 12 (head length HL $8.5 \mathrm{~mm}$ ), Dromiciops gliroides, ZIUT (HL $19 \mathrm{~mm}$ ), Perameles sp. ZIUT (HL $17.5 \mathrm{~mm}$ ), Macropus eugenii ZIUT (HL $29 \mathrm{~mm}$ ), and Thylogale billardierii (HL $13 \mathrm{~mm}$ ). Histological frontal sections were photographically recorded with a stereoscopic microscope (Leica MZ $16^{\circ}$ ) under natural light. Images were captured with a Leica DFC $420 \mathrm{C}^{\circ}$ digital camera and contrast was enhanced with Adobe Photoshop ${ }^{\circ}$. Table 1 lists the abbreviations used throughout the figures of this paper. The serial sections studied are deposited at the Universität Tübingen, collection of W. Maier from the former Zoologisches Institut, Germany (ZIUT)-some in long-term loan to the senior author's laboratory at the University of Zurich; Duke University Comparative Embryology Collection, currently housed at the Evolutionary Anthropology Department, Durham NC USA (DUCEC). Anatomical nomenclature follows mainly MacPhee [8] and Maier $[41,42,57]$, but as noted, terminology for the chondrocranium is diverse [12, 70]. Other useful sources of definitions and clarifications of skull anatomy are Wible and Rougier [92] and Mead and Fordyce [93]. The nomenclature of the ethmoidal region was discussed by Maier ([42], fig. 12.11), Freyer [94], and Rowe et al. [95].

\section{Chondrocranium: general features}

De Beer ([1]:p. 465) summarized much of the previous work on the mammalian chondrocranium and presented a list of marsupial features compared to those of "reptiles", monotremes, placentals, as well as ones unique to them (Table 2). This was the first comprehensive summary of the chondocranial anatomy of mammals, later followed by Roux [70] and Starck [71], whose contributions were also broadly comparative. Despite certain limitations, de Beer's [1] work on mammals is an excellent starting point. His statements form the basis of a research programme. Many of the listed features are discussed in the present paper. Below, we elaborate on another summary, Table 3, regarding hypotheses about the ethmoidal region [94].

In general, the marsupial chondrocranium has been characterized as having a lamina basalis of great breadth, a relatively large size of the otic capsule, and absence of the pila metoptica ([1]; Figs. 17 and 18). The latter is well established, the relative sizes of the parts are apparent when comparing three-dimensional models of mammals, but proper quantitative comparisons have never been made. The elements that contribute to the central stem or basicranial axis of the chondrocranium include the lamina trabecularis (=pars trabecularis), the 


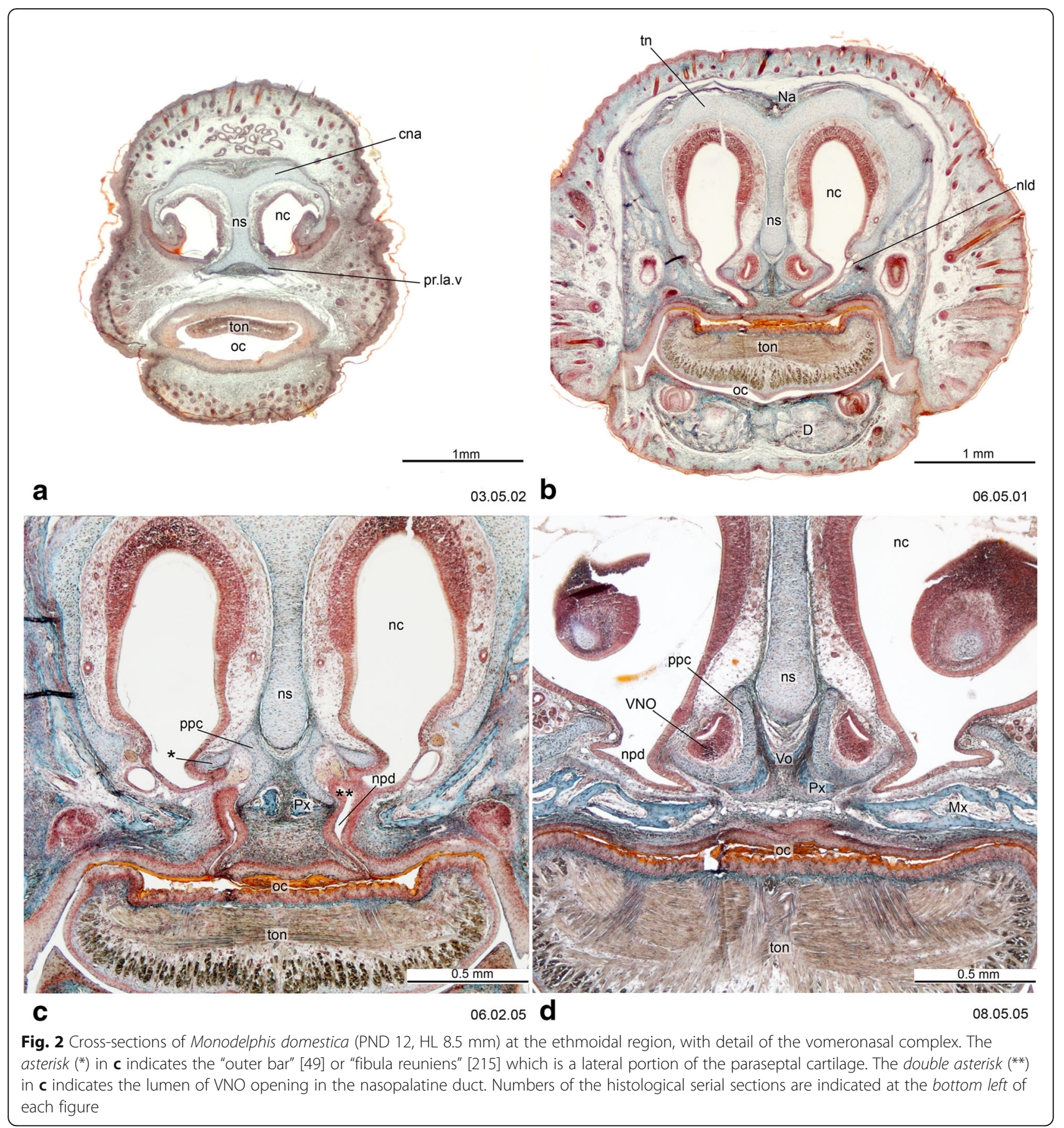

lamina hypophyseos (=hypophyseal plate) representing the Anlage of the basisphenoid, and the lamina basalis (=basal plate) representing the Anlage of the basioccipital [70]. The boundary between the pre-chordal and chordal domains [96], and also that between the neural crest and mesoderm, is located at the basisphenoidbasioccipital synchondrosis, as determined in a study on the laboratory mouse Mus musculus [97].

Several skull foramina are landmarks that help to identify some bones in the adult stage when sutures are obliterated. In most marsupials the internal carotid artery enters the skull through a carotid foramen located entirely within the basisphenoid, as in monotremes [30, 47, 65]. In some marsupials (e.g., Macropus eugenii), outgrowths of the basisphenoid/alisphenoid and wings of the pterygoid may secondarily enclose the artery; consequently the aperture is seen in ventral view immediately in front of the basisphenoid/basioccipital synchondrosis, as recorded in macerated skulls [65]. However, the carotid canal always crosses basisphenoid 


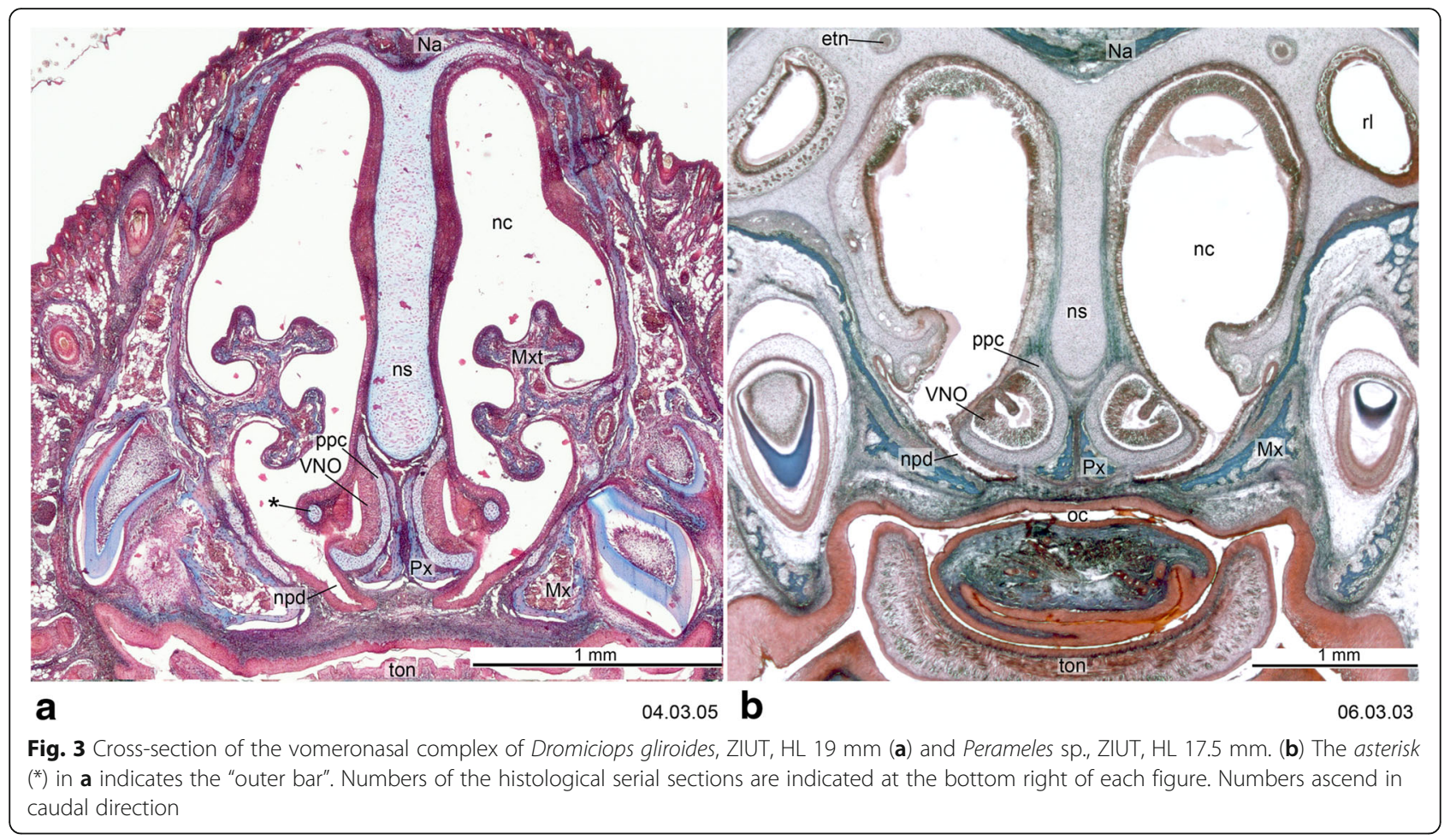

territory, as in other marsupials (Fig. 13). The foramen rotundum for the maxillary division of the trigeminal nerve $\left(\mathrm{CN} \mathrm{V}_{2}\right)$ opens in the alisphenoid [30, 63]. The transverse canal, for a vein that communicates with the cavernous sinus, lies entirely within the basisphenoid $[30,98]$. The sphenorbital fissure, a large gap that transmits nerves and vessels from the cavum epiptericum, opens on the medial wall of the orbit, between the orbitosphenoid and alisphenoid [30]. The ethmoidal foramen for a branch of the ophthalmic artery and the ethmoidal nerve (a branch of the ophthalmic division of the trigeminal nerve $\left.-\mathrm{CN} \mathrm{V}_{1}\right)[29,30]$ is usually in the suture between the frontal and orbitosphenoid, as reported for Didelphis albiventris, Dasyurus maculatus, Monodelphis domestica and M. brevicaudata [30].

The oval foramen, the aperture that transmits the mandibular division of the trigeminal nerve $(\mathrm{CN} \mathrm{V})$ from the middle cranial fossa to the outside of the skull, shows different patterns within marsupials $[34,99,100]$. The name foramen ovale is the primary exit of $\mathrm{CN} \mathrm{V}_{3}$ usually through an opening between the alisphenoid and the petrosal bone, or through the alisphenoid bone [99].

Outgrowths of the alisphenoid tympanic process may secondarily enclose $\mathrm{CN} \mathrm{V}_{3}[99,100]$. For this condition, an incomplete enclosure (i.e., presence of a secondary foramen, but not a canal) and complete enclosure (presence of a canal continuous with the primary aperture of $\mathrm{CN} \mathrm{V}_{3}$ ) has been recorded in didelphids ([100]: 30). The plesiomorphic condition for metatherians is the exit of
$\mathrm{CN} \mathrm{V}_{3}$ between the alisphenoid and petrosal bones (e.g., Mayulestes, Pucadelphys and Andinodelphys [14, 101]). Outgrowths of the alisphenoid enclosing the $\mathrm{CN} \mathrm{V}_{3}$ have been found in different taxonomic groups (e.g., Didelphidae, Dasyuridae, Thylacosmilidae and other Sparassodonta $[100,102,103])$.

\section{The nasal region}

The general studies of the chondrocranium cited above included sections on the ethmoidal region [42]. Some of Broom's [52, 104] contributions are devoted exclusively to this area. Currently, the complexity and disparity of the ethmoidal region among mammals is being investigated intensively using non-invasive imaging [105], including marsupials [35]. Rowe et al. [95] and Macrini [11] presented detailed studies of its ontogeny in the didelphids Monodelphis domestica and Caluromys philander, respectively. In her unpublished Master's thesis, Freyer [94] studied histological developmental series of $M$. domestica, and included a summary of 43 characters on the development of the ethmoidal region based on observations and a critical assessment of the literature for marsupial taxa. Freyer presented a list of features hypothesized to be part of the marsupial "Grundplan" sensu Hennig [106], meaning a list of character states for the last common ancestor of Marsupialia that are reconstructed based on phylogenetic considerations, and that included both plesiomorphic and apomorphic states in the context of mammal phylogeny (Table 3). 


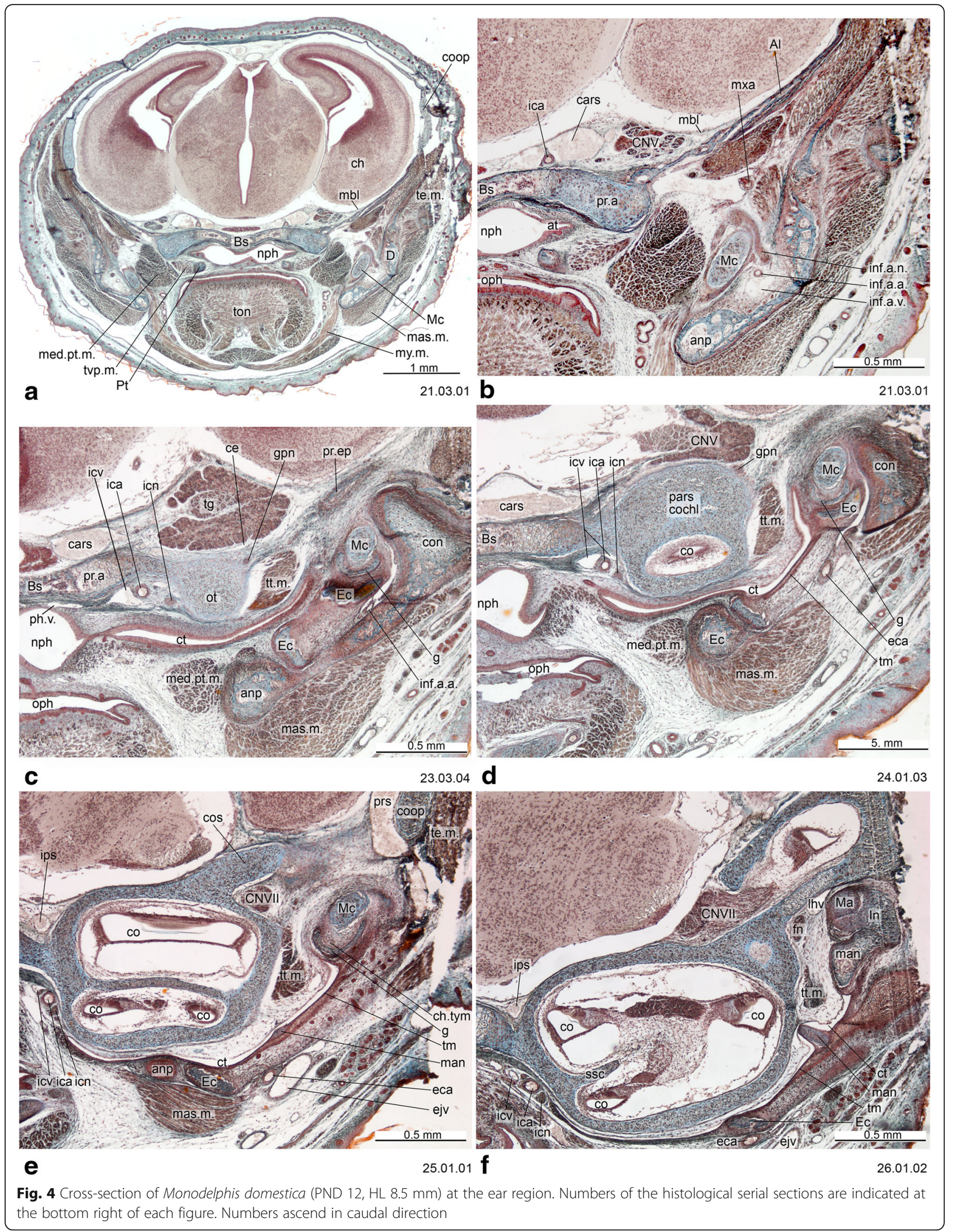



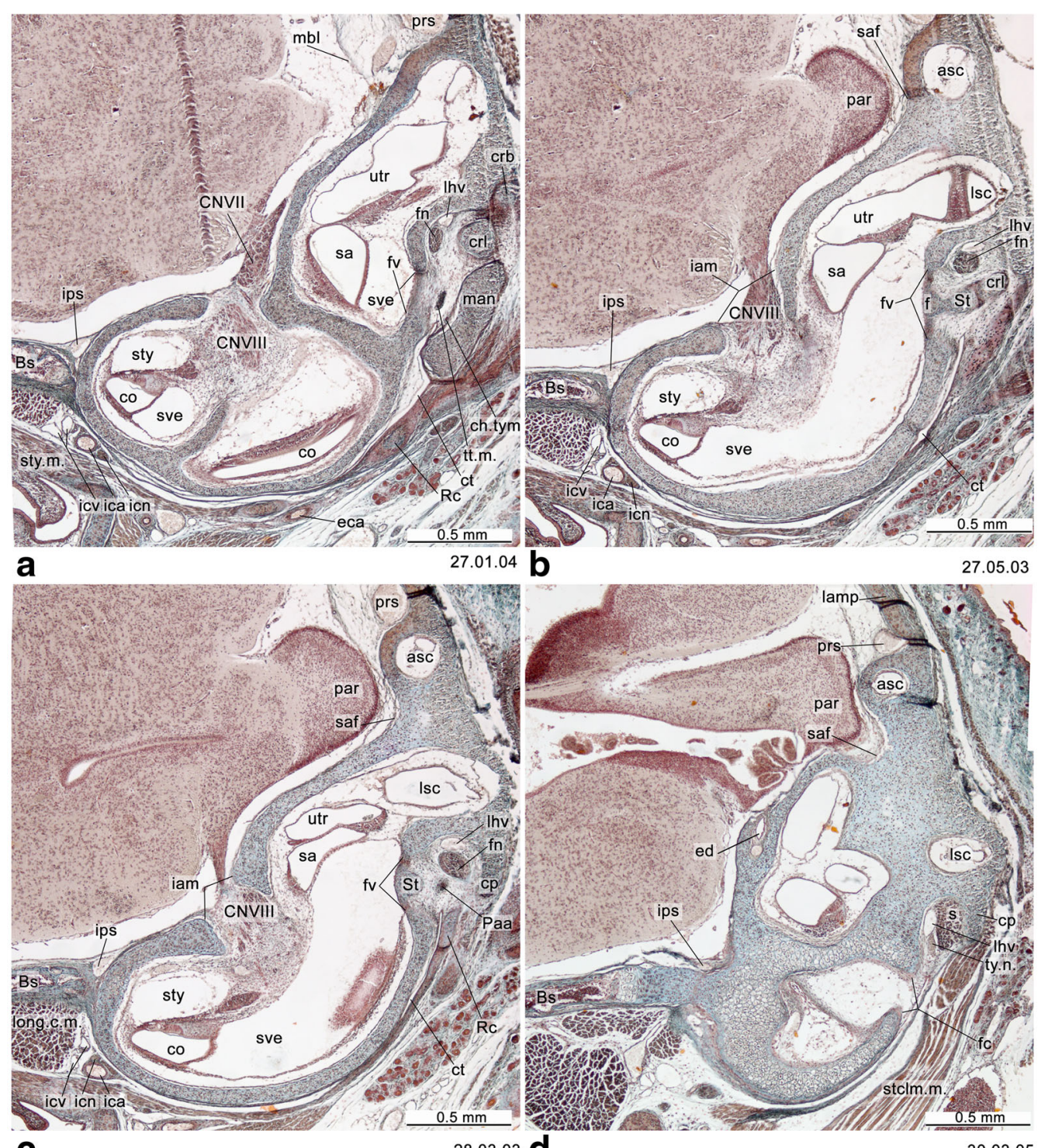

C

28.03.03 d

30.03 .05
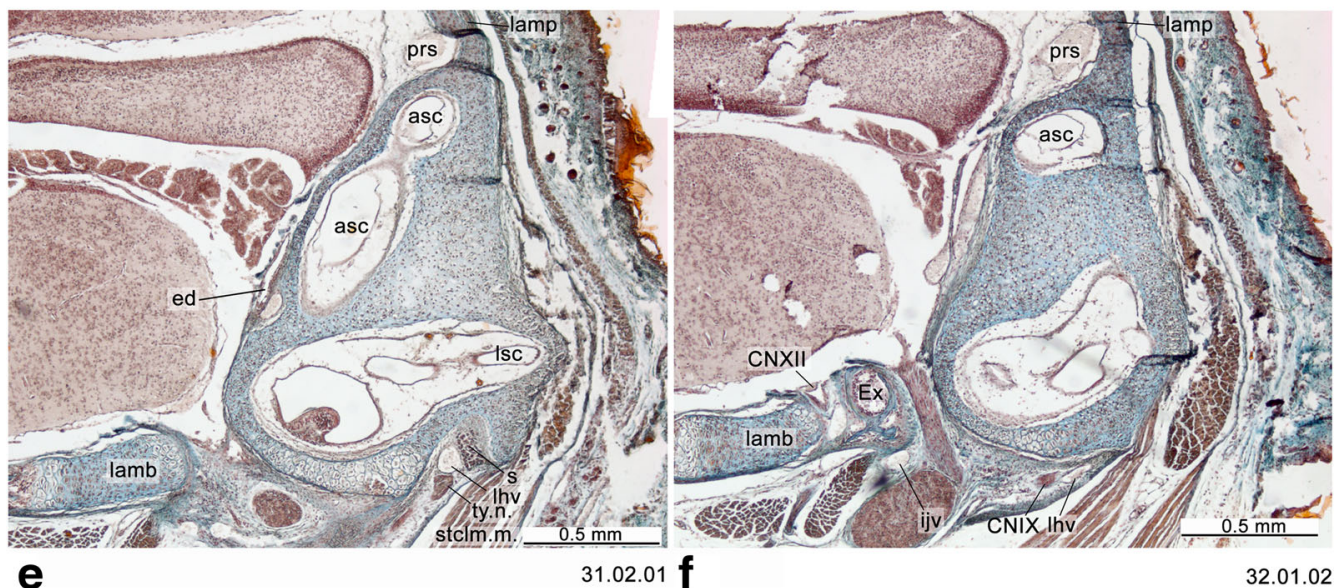

Fig. 5 Cross-section of Monodelphis domestica (PND 12, HL $8.5 \mathrm{~mm}$ ) at the level of the otic capsule. Numbers of the histological serial sections are indicated at the bottom right of each figure. Numbers ascend in caudal direction 


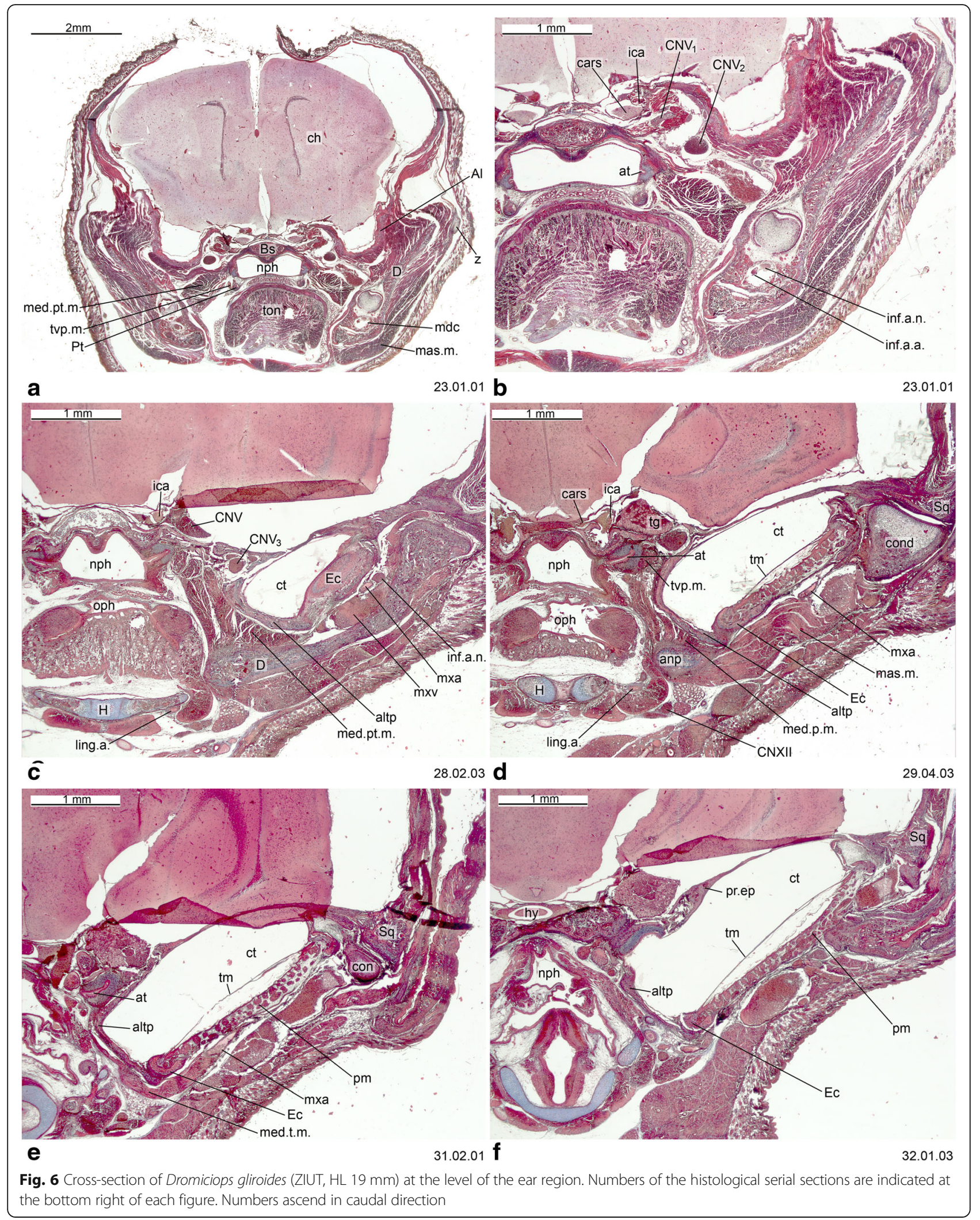



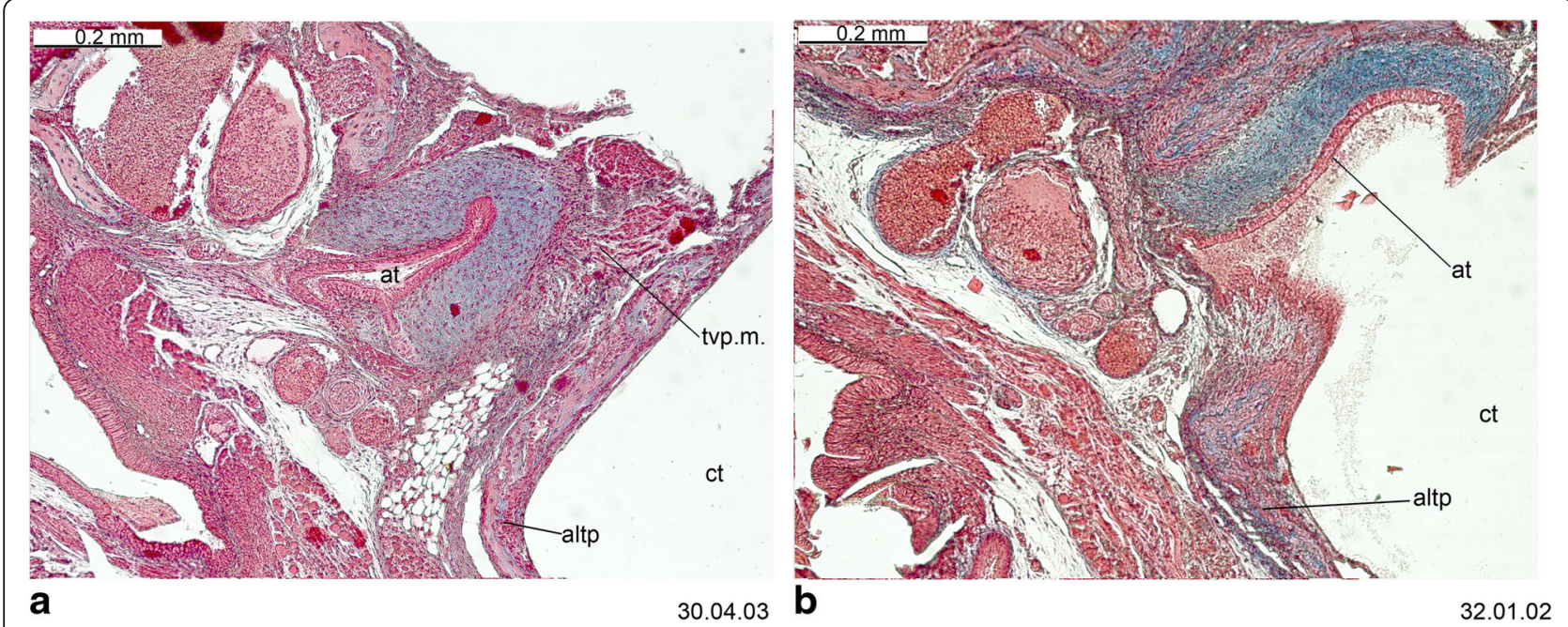

Fig. 7 Cross-section of Dromiciops gliroides (ZIUT, HL $19 \mathrm{~mm}$ ) with the fibrocartilaginous element of the auditory tube. Numbers of the histological serial sections are indicated at the bottom right of each figure

The overall construction of the nasal floor in marsupials is uniform, and all species studied to date have shown (1) presence of a vomeronasal organ and nasopalatine duct, (2) absence of a nasopalatine duct cartilage, and (3) a palatine cartilage absent or incipient (Fig. 19). Several other features of the nasal floor are variable and homoplastic across species, including the presence of glandular ridges and of an isolated dorsal process of the paraseptal cartilage [48, 107], while others represent features of potential phylogenetic significance. Sánchez-Villagra [48] presented a study of structures around the vomeronasal organ, including a matrix of 16 characters across species representing 13 "families" and six "orders" of marsupials. Some of the main conclusions are summarized as follows. The opening of the VNO into the upper end of the nasopalatine duct was present in the marsupial Grundplan (Figs. 2 and 3). Most marsupials have a large and horizontal anterior transverse lamina, the plesiomorphic condition, which becomes oblique in diprotodontians. Among the autapomorphies of clades found are the conspicuous internasal communication of perameliformes, the "tubelike" or ring-shaped paraseptal cartilage of vombatiformes, and an "anterior upper chamber" in the nasal cavity of Caenolestes sp., a structure forming from the contact between the superior septal ridge and a more inferior glandular-rich extension of the turbinal region $[94,104]$. A feature of Caluromys philander and of Australasian marsupials and Dromiciops, with the exclusion of perameliformes, is the middle and not dorsal connection of the outer bar to the paraseptal cartilage (Fig. 20).

A massive and broad cupula nasi anterior is characteristic of marsupials around the time of birth (Figs. 2 and 21) and can be hypothesized to be related to the perinatal biology of marsupials. Freyer [94] reported nerve bundles in the epithelium rostral to the cupula nasi anterior of Monodelphis domestica, possible nerves of $\mathrm{CN} \mathrm{V}_{2}$ that innervate the area which later develops into the rhinarium [108]. Previous studies have hypothesized a causal relation between the innervation and sensory anatomy of the area proximal to the cupula nasi anterior and the sensory biology of marsupials at birth [109114]. Taking eye development as a reference for comparing stages, Elsner [115] observed that the cupula nasi anterior develops much earlier in Monodelphis domestica than in the tree shrew Tupaia belangeri. The nasal openings in Monodelphis are laterally oriented at birth, which also makes functional sense.

A prominent structure in the nasal region of the mammalian chondrocranium is the nasal septum (Figs. 2 and 3 ), which is not fenestrated in marsupials, in contrast to the condition of some placentals $[65,116]$. One of the main unresolved issues in mammalian cranial comparative anatomy concerns the ossifications at and around the nasal septum [11, 70, 117, 118]. The ossification of the nasal septum can spread from the presphenoid, as reported for many marsupial taxa by Broom ([52, 104], although in some cases incorrectly interpreted), or it can be a separate, more rostral ossification, as reported by Rowe et al. [95] for Monodelphis domestica. The studies that have attempted to distinguish these two options, and thus decide if a mesethmoid is present or not, as discussed by Ferigolo [119], can suffer from the biases introduced by the stages examined, which may prevent the recognition of the actual pattern. Starck ([18], p. 43) wrongly supposed the "mesethmoid = ethmoid", inferring that ossification from a cartilaginous precursor in the posterior and dorsal portion of the nasal septum leads to this replacement bone. 

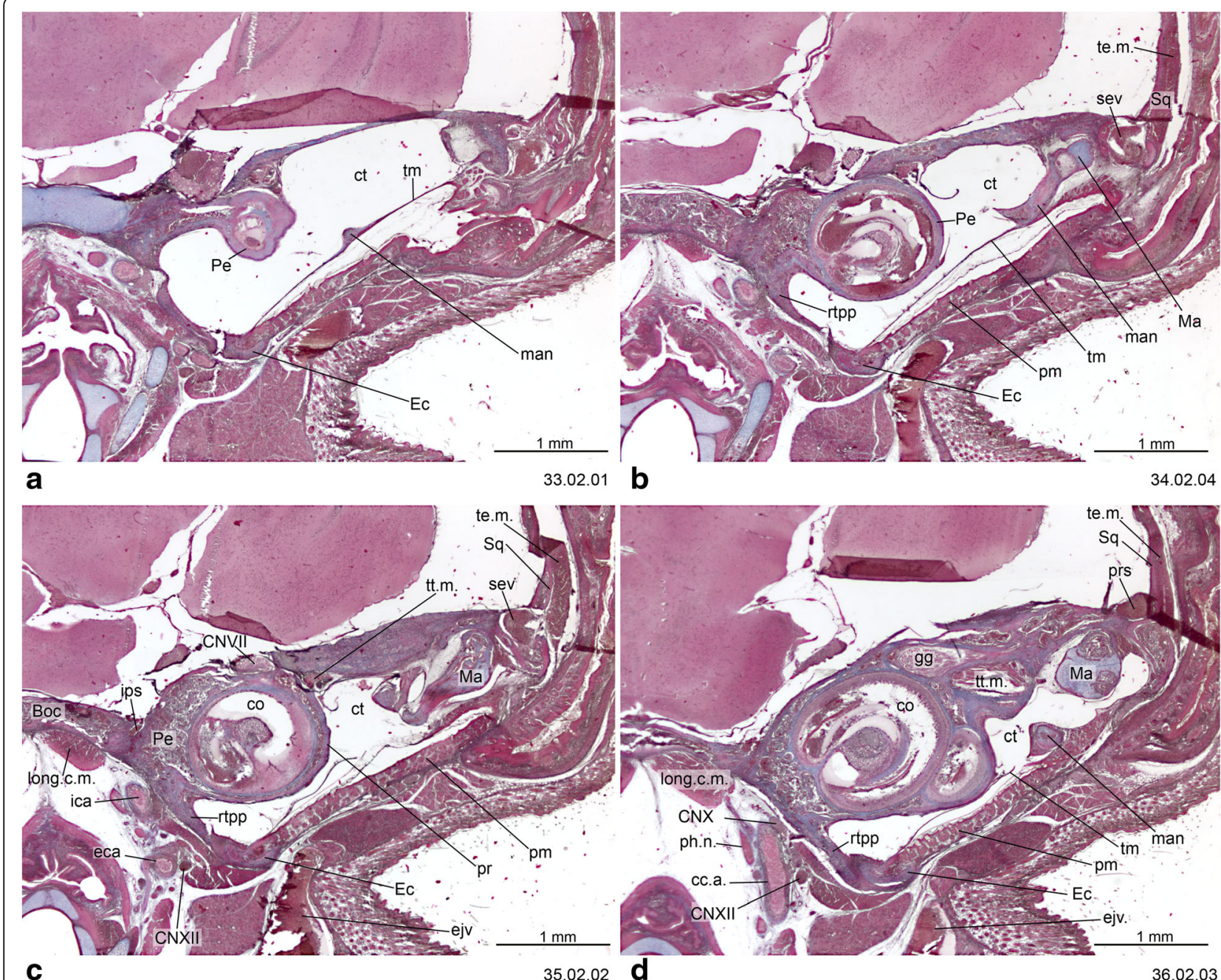

34.02 .04

Fig. 8 Cross-section of Dromiciops gliroides (ZIUT, HL $19 \mathrm{~mm}$ ) at the level of the rostral part of the petrosal (pars cochlearis). Note the extensive contribution of the rtpp to the auditory capsule. Numbers of the histological serial sections are indicated at the bottom right of each figure. Numbers ascend in caudal direction

The number of ossification centers are not necessarily reliable guides to homology in other areas of the skull, and examples of homologous bones with different numbers of ossification centers across species abound $[1,120]$. In the case of the mesethmoid, there is a terminological agreement-a separate ossification from the orbitosphenoid is by definition the sign of the existence of a mesethmoid [52]. The mesethmoid joins caudally the orbitosphenoid at a point near the optic chiasm. Confusion of the mesethmoid with other bones in that area of the ethmoidal region is easily avoidable. The ethmoid is a paired bone, whereas the mesethmoid is unique and median in its position; the v-shaped and unpaired vomer has clearly a more ventral position. Rowe et al. [95] reported for Monodelphis domestica that, whereas the mesethmoid ossifies in the third postnatal week from a single, median endochondral center, the ethmoid is paired and grows via the coalescence of multiple bilateral perichondral ossifications. As these elements co-ossify in adults, their distinctiveness and the homologies across taxa have been a source of disagreement and contradictory assessments in the literature. In one detailed study of its ethmoidal region, the mesethmoid is reported as lacking in Caluromys [11].

Understanding the transformation along the synapsid line in the area in which the ethmoidal and orbital region became closely connected (e.g., [121-123]) could provide important clues on the homologies of the bones involved, in parallel to the developmental approach taken in this paper and to comparative anatomical comparisons of extant forms. The fossil record documents the merging of wings of the orbitosphenoid to become the presphenoid. The ethmoid may represent a unique case of a true neomorph in the mammalian skull (cf. [123]; unpublished). 


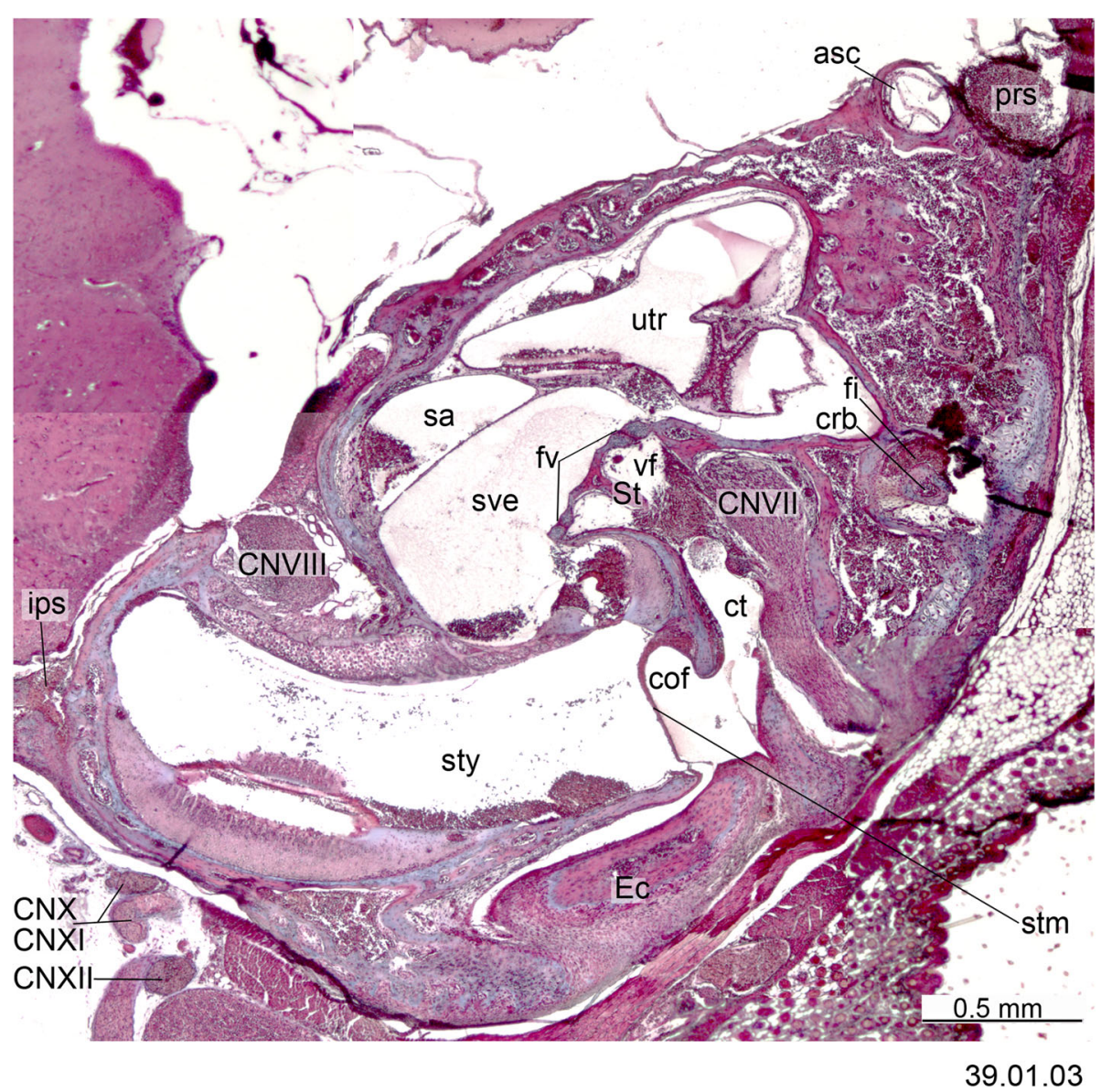

Fig. 9 Cross-section of the petrosal of Dromiciops gliroides (ZIUT, HL $19 \mathrm{~mm}$ ). Number of the histological serial section is indicated at the bottom right

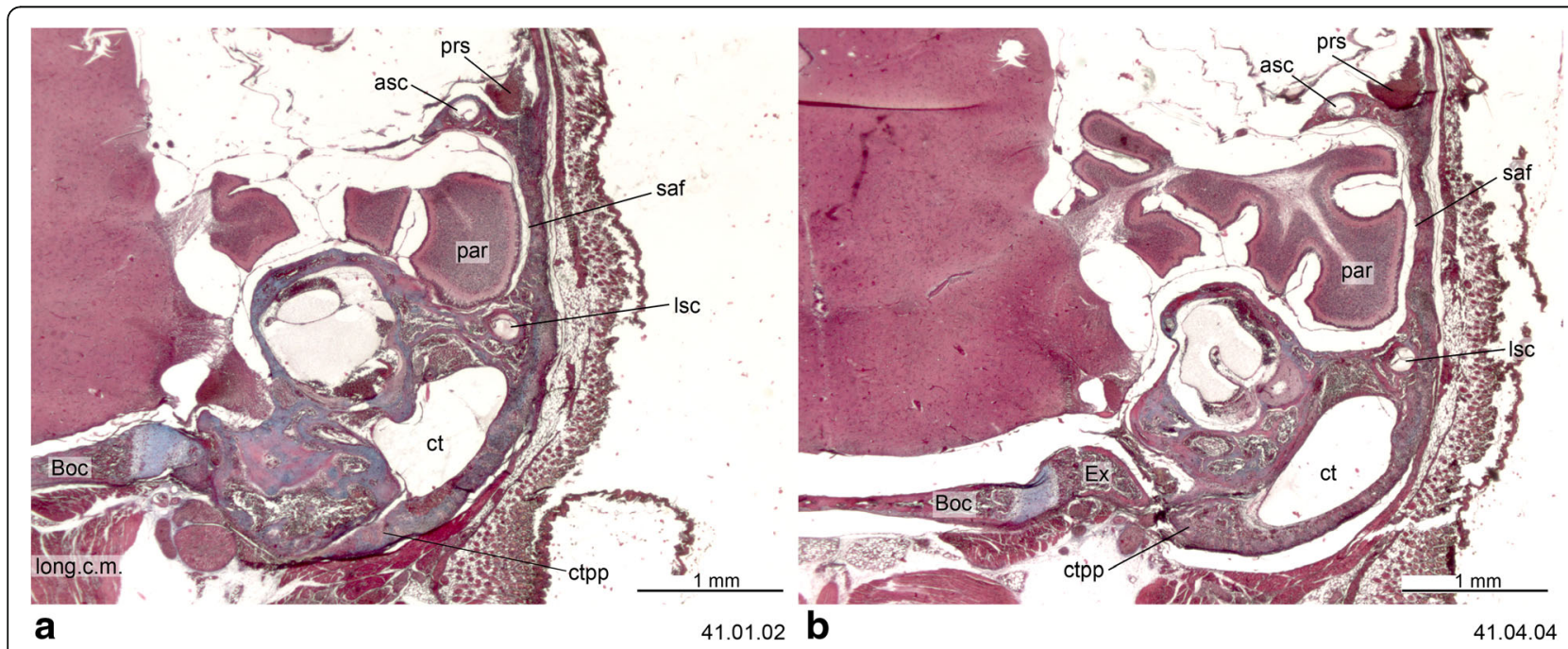

Fig. 10 Cross-section of Dromiciops gliroides (ZIUT, HL $19 \mathrm{~mm}$ ) at the level of the caudal part the petrosal (pars canalicularis). Note the extensive contribution of the ctpp to the tympanic floor. Numbers of the histological serial sections are indicated at the bottom right of each figure. Numbers ascend in caudal direction 


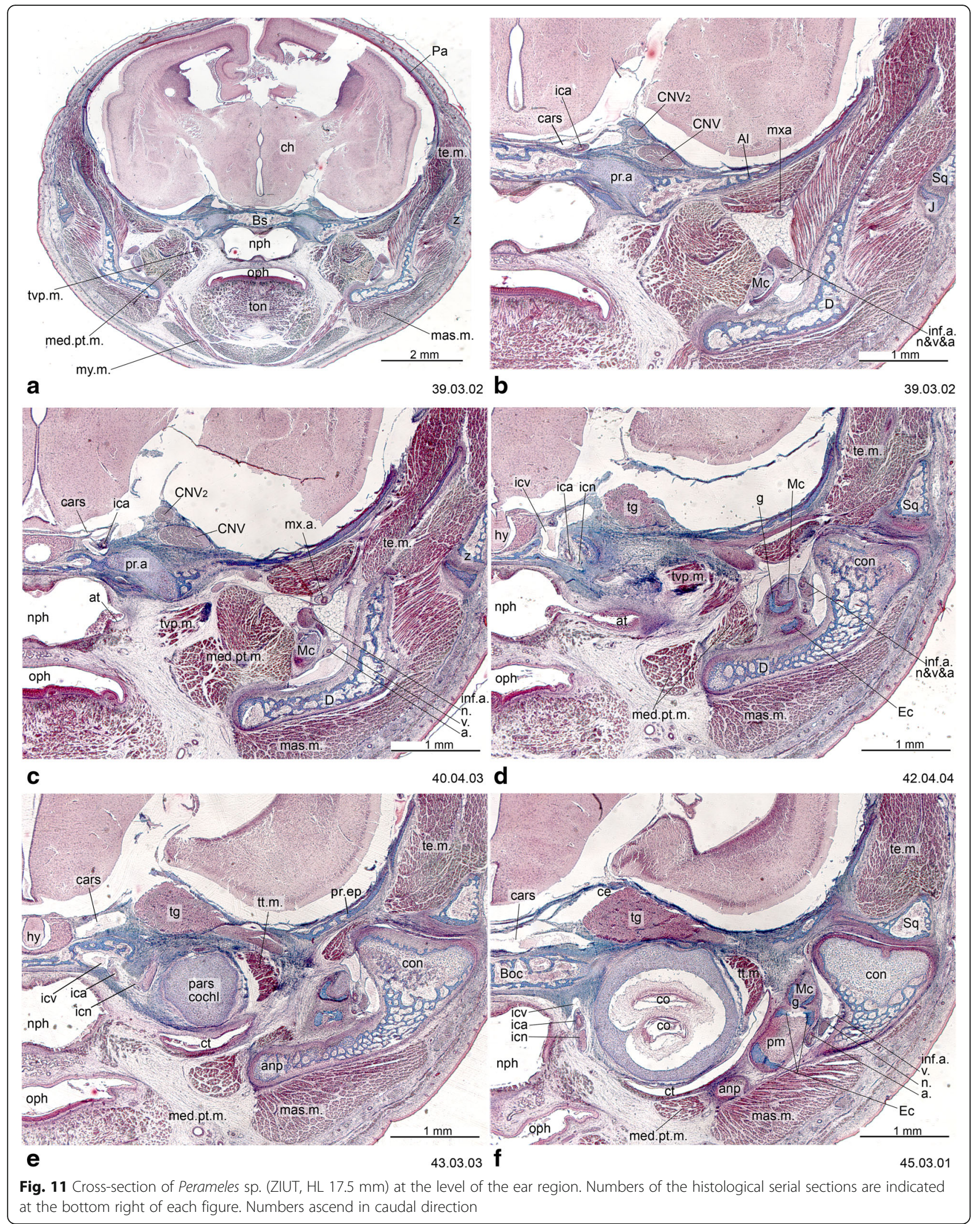




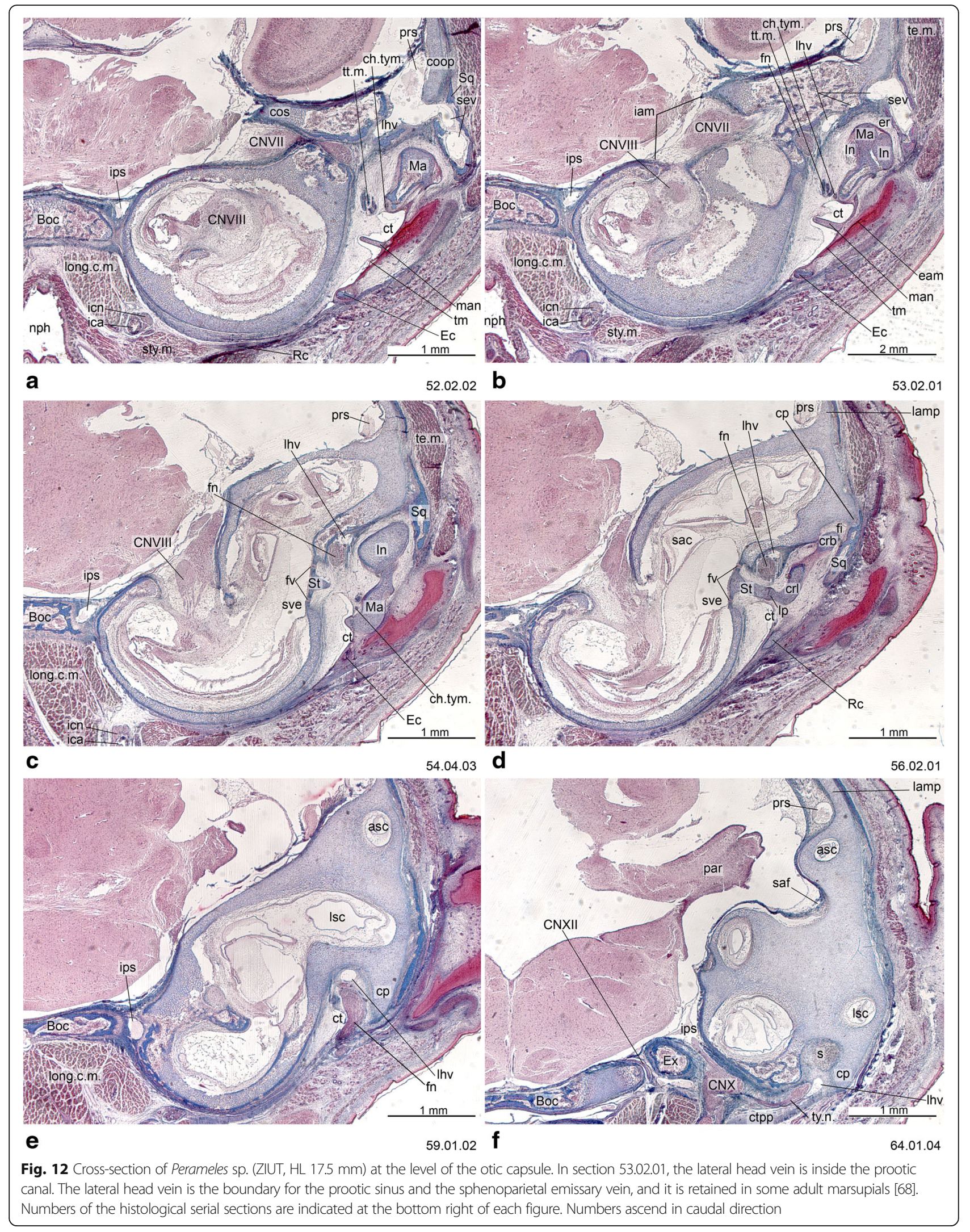



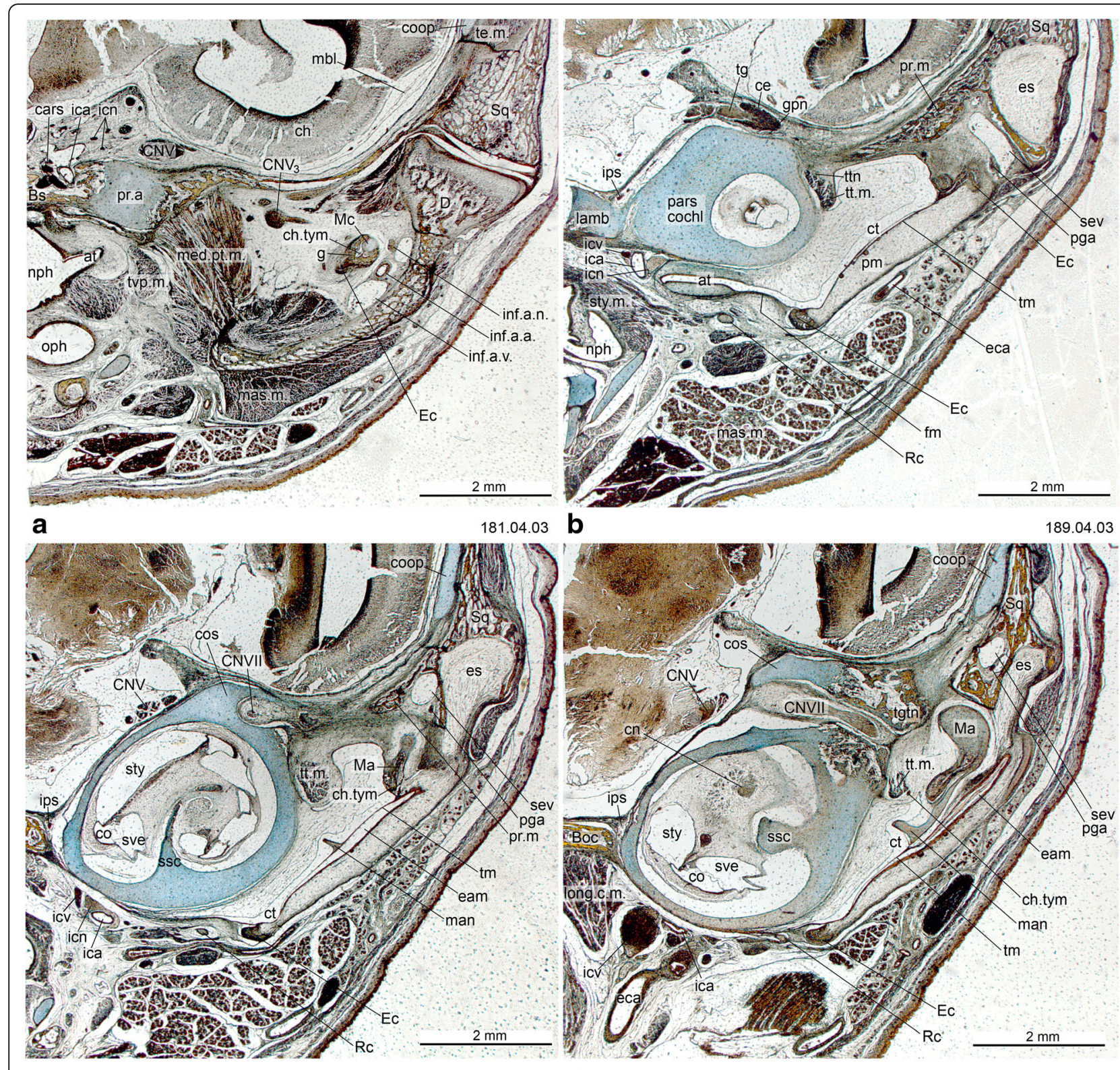

b

189.04 .03

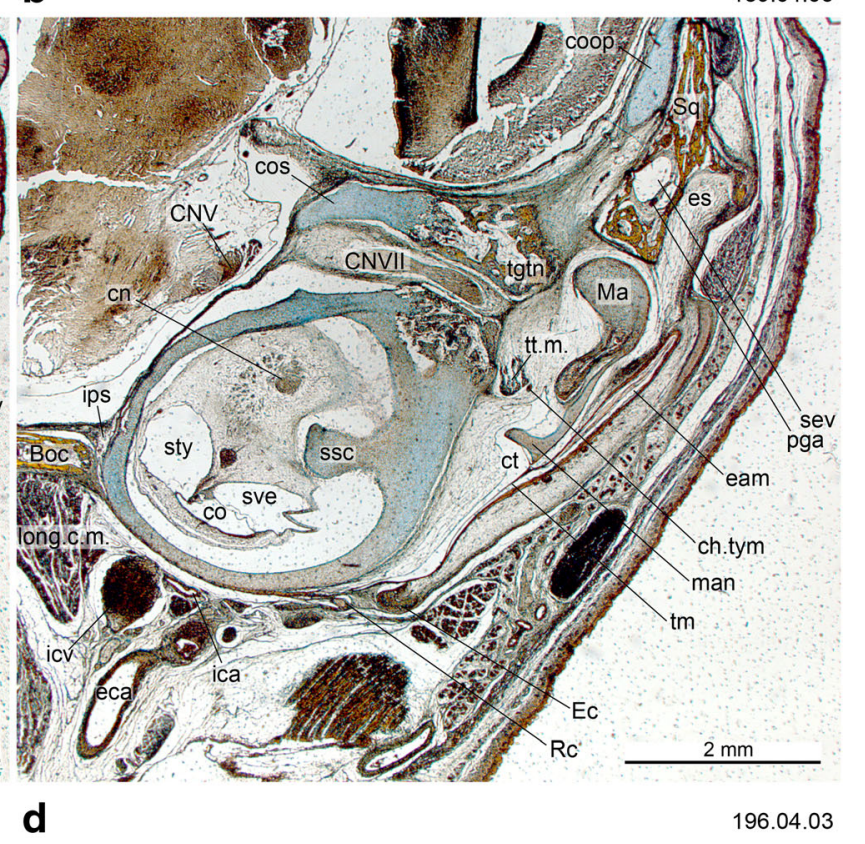

C

194.01.01

196.04 .03

Fig. 13 Cross-sections of Macropus eugenii (ZIUT, HL $29 \mathrm{~mm}$ ) at the level of the ear region. Note the large epitympanic recess in $\mathbf{b}$ and c. Numbers of the histological serial sections are indicated at the bottom right of each figure. Numbers ascend in caudal direction

The presence of the parasphenoid is less known in marsupials, as it appears when present as a very small ossification ventral to the basisphenoid-basioccipital suture (e.g., [124, 125]) and as we have observed in a section of Didelphis sp.

The timing and number of centers of ossification of the bones of the orbitotemporal area adjacent to the ethmoidal region have been documented in Monodelphis domestica ([63], as summarized by [30]). The presphenoid (midline rod) and orbitosphenoids (arms) arise on postnatal days 13 and 14 from three ossification centers that fuse to form a T-shaped structure by postnatal day 16. The basisphenoid arises from a single center of ossification on postnatal day 5. Each alisphenoid arises from two centers of ossification on postnatal day 4 , both fusing by postnatal day 7 (cf. [57]). The basisphenoid and alisphenoid are fused together by postnatal day 25 ([30], page 151).

\section{Primary braincase wall and other chondrocranial features}

The sidewall of the primary braincase of tetrapods is formed by three vertical cartilaginous pillars: the pila praeoptica, pila metoptica and pila antotica, which during 


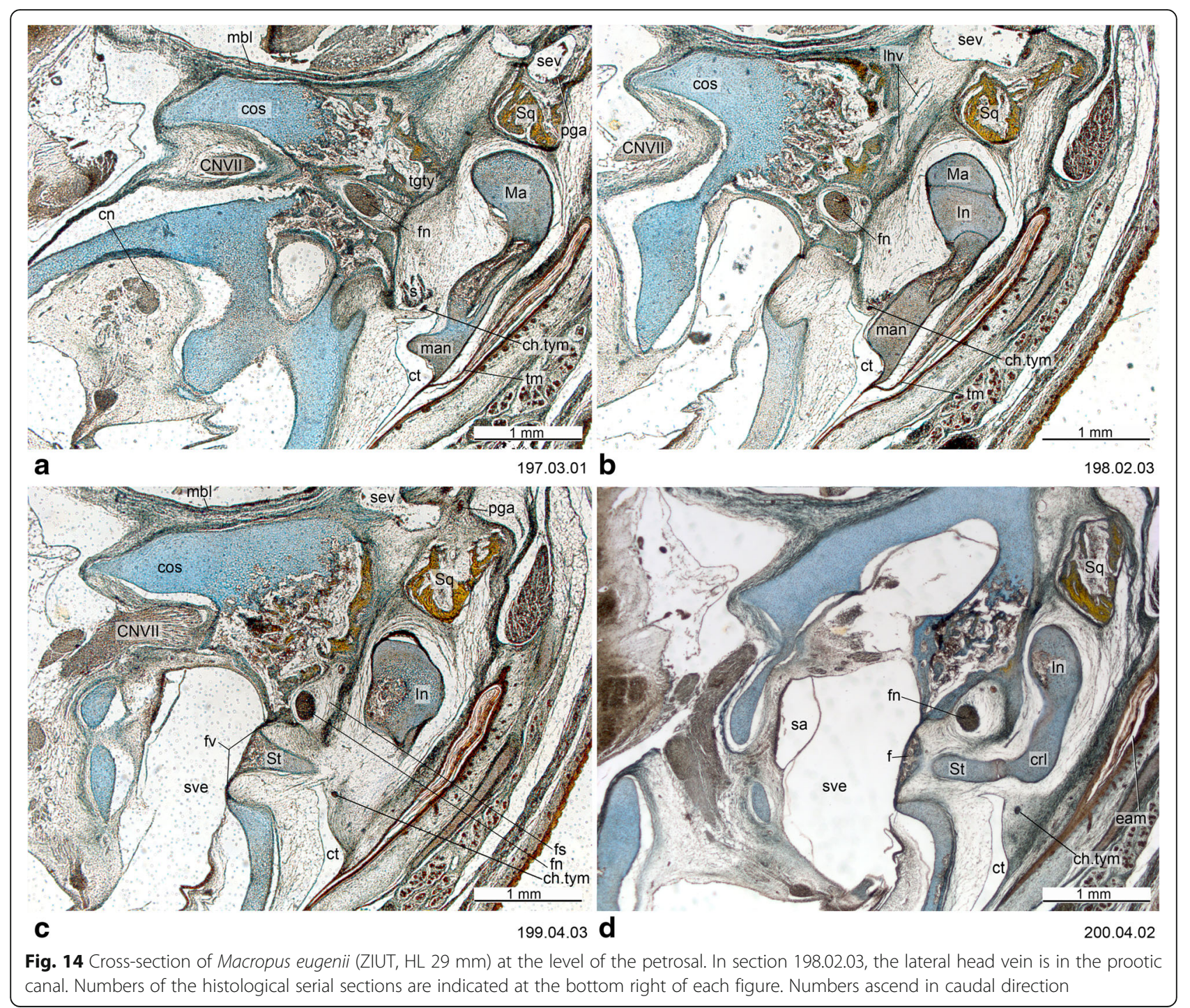

ontogeny grow between certain cranial nerves [1]. In placentals, the pila antotica is absent, leaving a common opening for the exit of CN III-CN VI. In marsupials, the pila metoptica and pila antotica are absent, which results in a large opening for $\mathrm{CN}$ II-CN VI (e.g., [12, 45, 73, 74, 126]). Although CN II is included within the sphenorbital fissure only in marsupials, a similar opening in placentals is called by the same name. In placentals, CN II is enclosed in a separate optic foramen [127].

In addition to the pilae, the other elements that contribute to the primary braincase wall in marsupials are the ala orbitalis, commissura orbitonasalis, commissura orbitoparietalis and commissura suprafacialis (Fig. 17). The braincase wall is completed by the secondary wall; the ala temporalis with the lamina ascendens (= ascending process) and the membrana sphenoobturatoria, the last two Anlagen of the alisphenoid [73, 74] (Fig. 16).
Although the secondary wall is not part of the chondrocranium [128], it is relevant to discuss it here.

The cartilaginous ala temporalis of marsupials is homologous to the basal and ascending processes of the palatoquadrate of reptiles [42, 57]. The alisphenoid starts to grow intramembranously from the perichondrium of the ascending process of the ala temporalis, appositionally on the membrana sphenoobturatoria, and endochondrially within ala temporalis itself $([42,57,58]$; Fig. 16$)$.

The ascending process of the ala temporalis has different relationships with the branches of the trigeminal nerve $(\mathrm{CN}$ V) among marsupials (Table 4). The differences in the relationships between the ala temporalis and the branches of the trigeminal nerves in mammals triggered extensive discussion regarding the homology of the alisphenoid bone [76, 128]. Peripheral nerves develop much earlier than the first skeletal structures and even homologous cartilaginous 


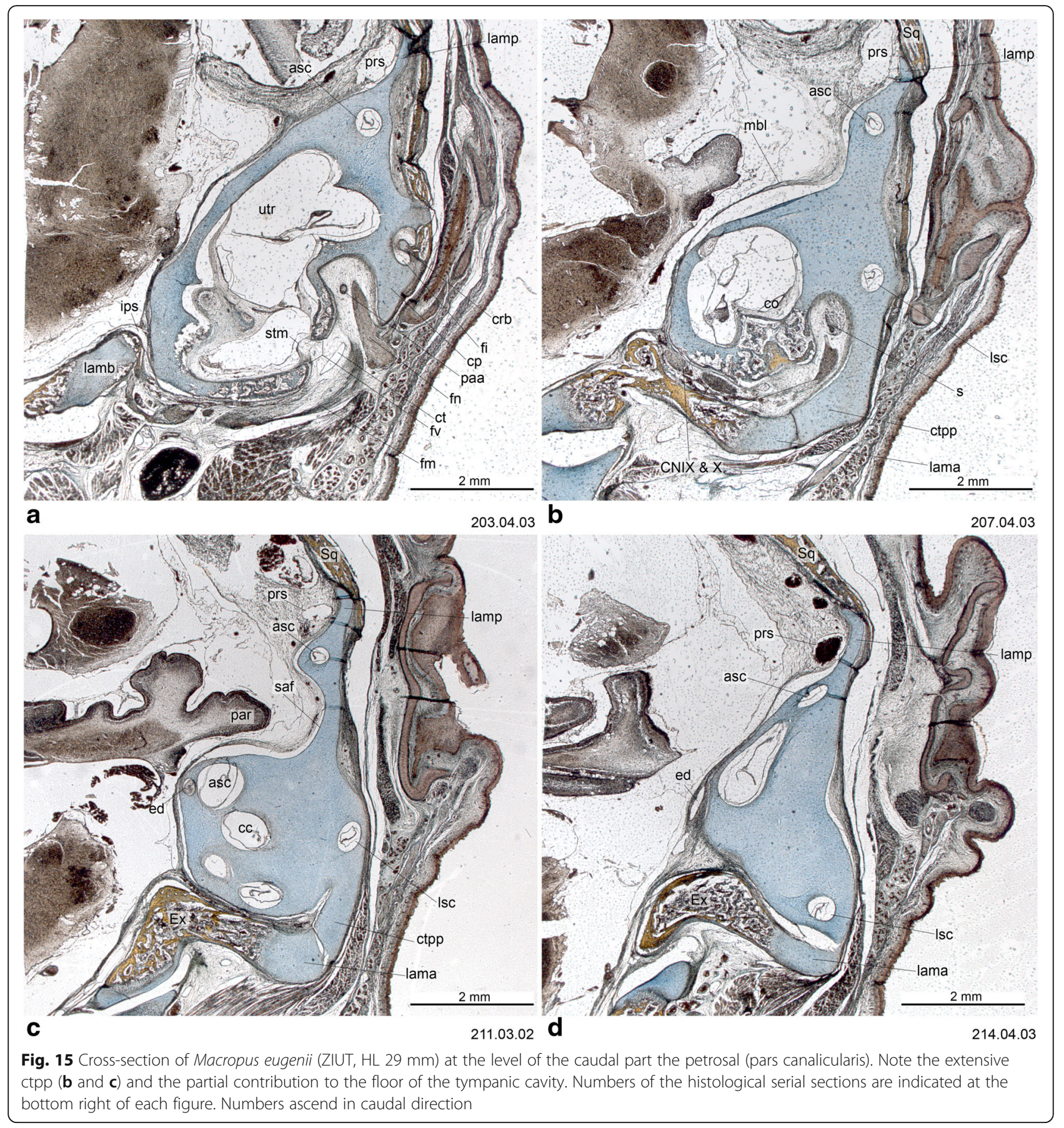

and bony elements may develop topographically in different ways to accommodate the primary organization of the head organs $[42,57,74]$.

In many adult marsupials, the $\mathrm{CN} \mathrm{V}_{2}$ exits the skull through its own aperture, the foramen rotundum. This can be a consequence of the ala temporalis eventually surrounding $\mathrm{CN} \mathrm{V}_{2}$, to be replaced later by intramembranous growth of the alisphenoid (e.g., Vombatus, Trichosurus, Sminthopsis) or by appositional deposition of bone (e.g., Didelphis, Monodelphis, as in some placentals) [57, 74, 126, 128, 129]. The latter condition seems to be secondary, and the presence of a foramen rotundum may be a convergent feature of different groups of mammals [74].

The commissura orbitoparietalis is a bar of cartilage on the side wall of the cranium (Figs. 16 and 17). There is no clear boundary between it and the lamina parietalis. The lamina parietalis is a thick plate of cartilage; its ventral limit is the dorsal margin of the canalicular part of the otic capsule [54] (Figs. 5, 12 and 15). 


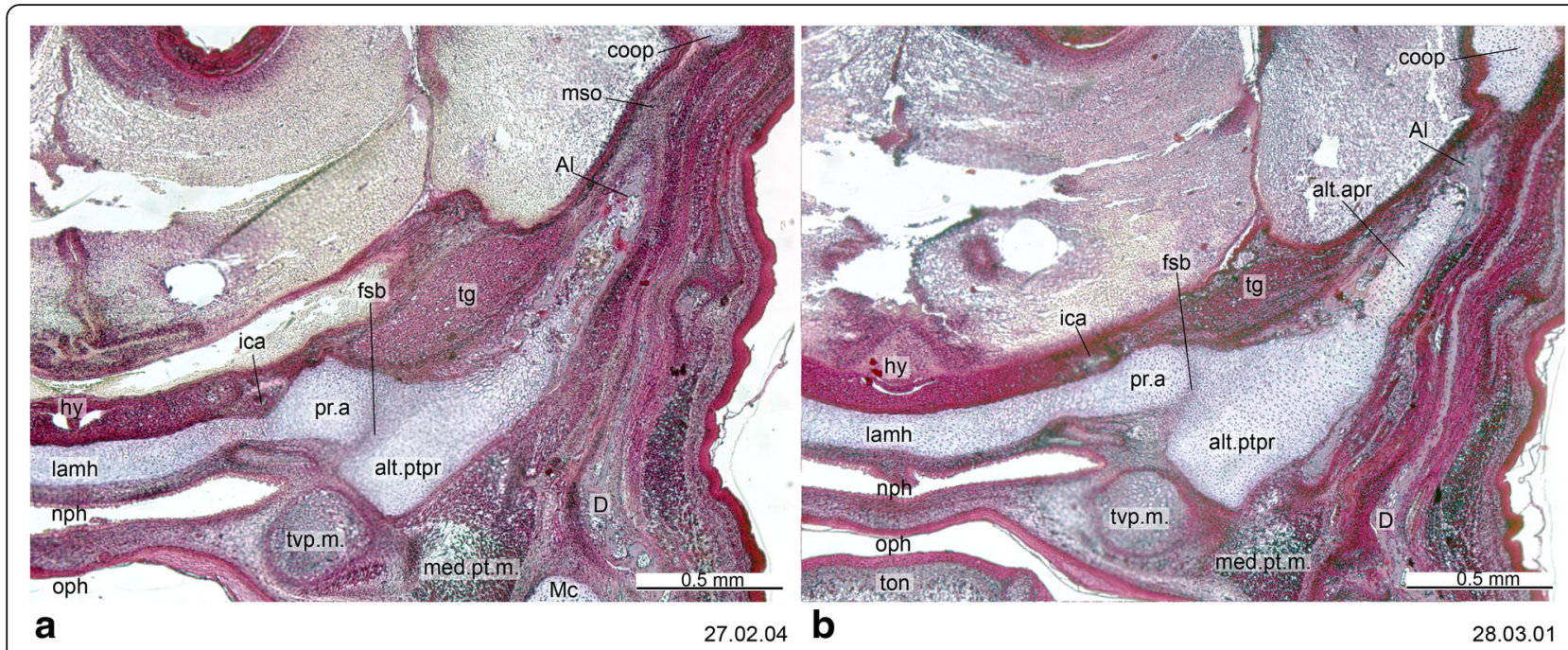

Fig. 16 Cross-section of Thylogale billardierii (ZIUT, HL $13 \mathrm{~mm}$ ) at the level of the hypophysis. The chondrocranial braincase wall if formed by the lamina ascendens of the ala temporalis and the membrana sphenoobturatoria, which in this specimen have started ossification. Numbers of the histological serial sections are indicated at the bottom right of each figure. Numbers ascend in caudal direction

The ascending process of the ala temporalis reaches the commissura orbitoparietalis early in ontogeny, forming part of the secondary lateral wall of the braincase (Fig. 16) and providing mechanical support to withstand the pull of the adductor muscles during suckling [42, 57]. The strong commissura orbitoparietalis and the membrana sphenoobturatoria provide initial attachment area for the strong temporalis muscle [57].

Early in ontogeny, the trigeminal ganglion is situated in the cavum epiptericum, between the membrane limitans and the membrana sphenoobturatoria [57, 60]. In neonates, the trigeminal ganglion is large, occupying most of the cavum epiptericum ([57]; Fig. 16). This precocious development of the trigeminal system might be interpreted as being related functionally to the suckling activity of the neonate [42, 57], as in the case of the buccinator muscle, which is innervated by sensory branchs of $\mathrm{CN} \mathrm{V}_{3}$ and directly involved in suckling. However, monotremes also have a large trigeminal ganglion early in ontogeny, and they do not suckle [130].

The processus alaris is the lateral projection of the hypophyseal plate of the central stem [8] (Figs. 4, 11, 13 and 16) which becomes continuous with the ala temporalis [1]. In earlier ontogenetic stages, there is gap between the procesus alaris and the ala temporalis, the fissura basipterygoidea [42, 57, 58] (Fig. 16). In placentals, the processus alaris is often connected to the otic capsule by a cartilaginous bridge, the alicochlear commissure. The alicochlear commissure is characteristically missing in marsupials according to De Beer ([43; see also [57]).

In the posterior portion of the chondrocranium, the principal element is the pila occipitalis. This fuses with the lamina parietalis to form the portion of the chondrocranium which surrounds the foramen magnum. The occipital condyles are formed by the pila occipitalis. In the back of the chondrocranium, all marsupials studied to date are characterized by double hypoglossal foramina, as opposed to the single foramen characteristic of most placentals (Table 2; [65]).

\section{Lower jaw and middle ear ossicles}

The transformations of the middle ear and associated jaw joint anatomy [131] are classic subjects in mammalian anatomy and paleontology [132-137], and conditions in marsupials have figured prominently in their interpretations [59, 138, 139]. The evolutionary transformation involves complex changes in the craniomandibular hinge from a primary quadrate-articular to a secondary dentary-squamosal jaw joint, and the progressive reduction and detachment of the postdentary bones as a series of ossicles transmitting the sound waves in the middle ear $([59,140])$.

Recently, Ramírez-Chaves et al. [141] reviewed and quantified several structures involved in this evolutionary transformation based on ontogenetic material for six species representing three major marsupial clades. The plesiomorphic mammalian pattern for the Anlagen of the middle ear bones is for them to be medially shifted from the mandible $[42,72]$. In marsupials, this relocation is reportedly much less marked, which is considered derived [42, 141].

There is a displacement of the middle ear bones in the posterior direction during ontogeny in all mammals. Based on a study of Monodelphis domestica, it was suggested that this is associated with braincase enlargement and tied to the detachment of structures building part of 
Table 1 List of the the abbreviations used throughout the figures of this paper

\section{a., artery}

$\mathrm{Al}$, alisphenoid

alo, ala orbitalis

alt.ptpr, ala temporalis processus ptegygoideus

alt.apr, ala temporalis, processus ascendens

altp, alisphenoid tympanic process

anp, angular process of dentary

asc, anterior semicircular canal

at, auditory tube

Boc, basioccipital

Bs, basisphenoid

cars, cavernous sinus

cc, crus commune

cc.a., common carotid artery

ce, cavum epiptericum

cf, carotid foramen

ch, cerebral hemisphere

ch.tym, chorda tympany n. (CN VII)

cn, cochlear n. (CN VIII)

cna, cupula nasi anterior

$\mathrm{CN} V$, trigeminal $\mathrm{n}$.

$\mathrm{CN} \mathrm{V} \mathrm{V}_{1}$, ophthalmic branch of trigeminal $\mathrm{n}$.

$C N V_{2}$, maxillary branch of trigeminal $n$.

$\mathrm{CN} \mathrm{V}$, mandibular branch of trigeminal $n$.

CN VII, facial $n$.

CN VIII, vestibulocochlear $n$.

CN IX, glossopharyngeal $n$.

CN $X$, vagus $n$.

$\mathrm{CN} \mathrm{XI}$, accessory $\mathrm{n}$.

CN XII, hypoglossal $n$.

$\mathrm{cO}$, cochlear duct

cof, cochlear fossula (= fossula fenestra cochleae)

con, dentary condyle

coop, commisura orbitoparietalis

cos, commisura suprafacialis

$\mathrm{cp}$, crista parotica

crb, crus breve of incus

crl, crus longum of incus

ct, cavum tympani

ctpp, caudal tympanic process of petrosal

D, dentary

eam, external acoustic meatus

Ec, ectotympanic

eca, external carotid a.

ed, endolymphatic duct

ejv, external jugular vein

er, epitympanic recess

es, epitympanic sinus

etn, ethmoidal nerve $\left(C N V_{1}\right)$

Ex, exoccipital

$f$, footplate of stapes

$\mathrm{fc}$, fenestra cochleae

fi, fossa incudis

$\mathrm{fm}$, fibrous membrane of the tympanic cavity

fn, facial nerve (CN VII)

Fr, frontal

$\mathrm{fs}$, facial sulcus

$\mathrm{fsb}$, fissura basipterygoidea

$\mathrm{fv}$, fenestra vestibuli

g, gonial

gg, geniculate ganglion (CN VII)

gpn, greater petrosal nerve (CN VII)

$\mathrm{H}$, hyoid

hy, hypophysis

iam, internal acoustic meatus

ica, internal carotid a.

icn, internal carotid $n$.

icv, internal carotid $v$.

ijv, internal jugular v.
Table 1 List of the the abbreviations used throughout the figures of this paper (Continued)

In, incus (= anvil)

inf.a.a., inferior alveolar a.

inf.a.n., inferior alveolar n. (CN V $)_{3}$

inf.a. v., inferior alveolar v.

Ipa, interparietal

ips, inferior petrosal sinus

lama, lamina alaris

lamb, lamina basalis

lamh, lamina hypophyseos

lamp, lamina parietalis

Ihv, lateral head v. (= vena capitis lateralis)

ling.a., lingual artery

long.c.m., longus capitis m.

$\mathrm{Ip}$, lenticular process of incus

Isc, lateral semicircular canal

It, lamina trabecularis

Ita, lamina transversalis anterior

m., muscle

Ma, malleus (= hammer)

man, manubrium of malleus

mas.m., masseter $m$.

mbl, membrane limitans

Mc, Meckel's cartilage

mdc, mandibular canal

med.pt.m., medial pterygoid m.

mso, membrana sphenoobturatoria

Mx, maxilla

mxa, maxillary a.

$m \times v$, maxillary $v$.

$m x t$, maxiloturbinate

my.m., mylohyoid m

n., nerve

$\mathrm{Na}$, nasal

nc, nasal cavity

nld, nasolacrimal duct

npd, nasopalatine duct

nph, nasopharynx

ns, nasal septum

ob, outer bar

oc, oral cavity

oph, oropharynx

ot, otic capsule

$\mathrm{Pa}$, parietal

paa, element of Paaw

par, paraflocculus of cerebellum

pars cochl, pars cochlearis

$\mathrm{Pe}$, petrosal

pga, postglenoid artery

pgv, postglenoid vein

ph.con.m., pharyngeal constrictor $\mathrm{m}$.

ph.n., pharyngeal nerve

ph.v., pharyngeal vein

pm, tissues of the membranous meatus

pn, paries nasi

ppc, paraseptal cartilage

ppo, pila praeoptica

pr, promontorium

pr.a, processus alaris

pr.ep, processus epitympanicus

pr.la.v, processus lateralis ventralis

pr.m, processus medialis (= medial process of Sq.)

pr.ma, processus mastoideus

prs, prootic sinus

psc, posterior semicircular canal

Pt, pterygoid

Px, premaxilla

Rc, Reichert's cartilage

$\mathrm{rl}$, recessus lateralis 
Table 1 List of the the abbreviations used throughout the figures of this paper (Continued)

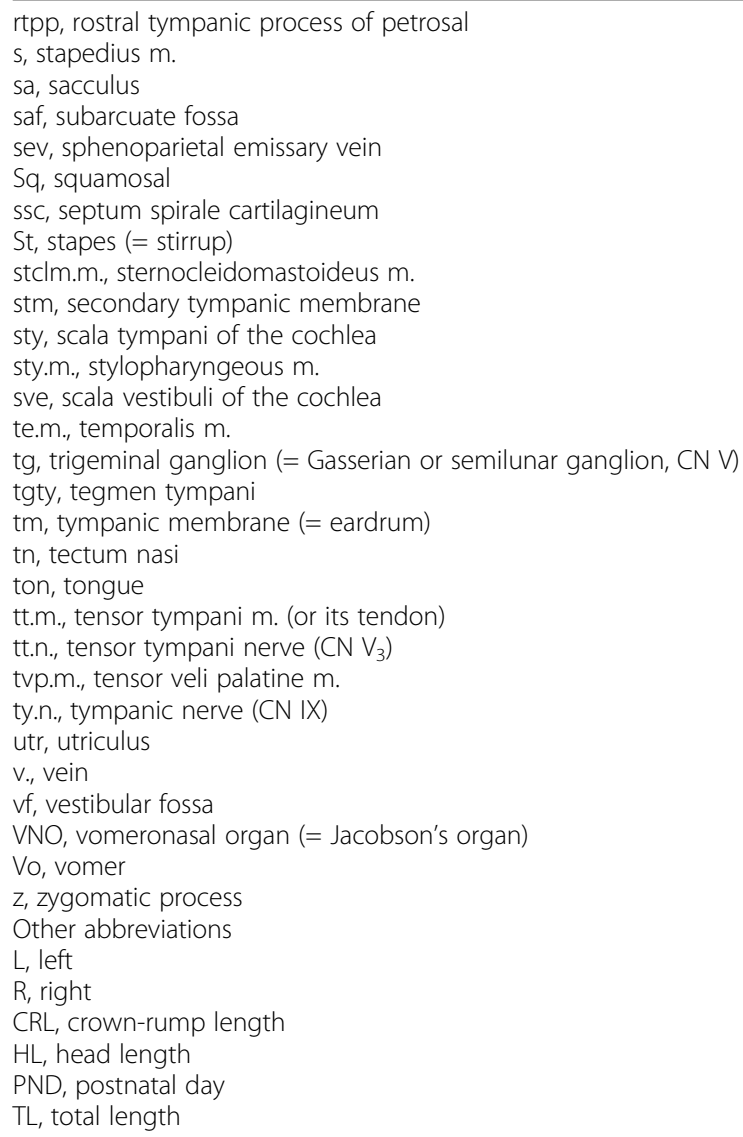

the middle ear in the adult [21]. This hypothesis stimulated productive examination of rates of development in structures in different marsupials [142] and comparisons with the fossil record [143, 144]. Alternatively, Ramírez-Chaves et al. [141] presented evidence that dental function, as indicated by molariform tooth eruption, better correlates with the detachment and ossification of the middle ear ossicles than brain expansion, and that the negative allometry of the ossicles begins after their detachment.

Meckel's cartilage forms in early ontogenetic stages; in marsupials it is usually a conspicuous structure, reportedly relatively larger in relation to the rest of the developing skull than in placentals $[145,146]$. This question deserves further examination. The size of the Meckel's cartilage changes through development (Fig. 22), and some illustrated stages of placentals (e.g., Rousettus aegypticus, [18]) show a fairly robust Meckel's cartilage. In early ontogenetic stages, Meckel's cartilage is lodged in a longitudinal groove, the medial trough of the dentary, which becomes shallower or disappears in later ontogenetic stages [42]. In marsupials at birth, the lower jaw is still suspended by the primary joint, with the incus supported by Meckel's cartilage
Table 2 Features listed by de Beer [1] as characteristic of marsupials. Several of the features do not concern the chondrocranium directly, but are listed here for the sake of completeness. The titles of each of three sections are taken from de Beer's [1] formulation

"Reptilian" features of marsupials that are shared with monotremes and are absent in placentals ([1]:465):

"the basal plate is broad"

"the cochlear capsules are small"

"the canalicular capsules lie directly above the cochlear, and the medial walls of the auditory capsules thus form the main part of the lateral walls of the cranial cavity in the posterior region"

"the parietal plates are low"

"the occipital arches are vertical"

"the tegmen tympani is very small and there is no lateral prefacial commisure"

"the incus lies dorsally to the malleus"

"the stapes is columelliform"

"the orbital cartilage and the sphenoethmoid and orbitoparietal commisures form a wide band"

"the carotid foramina pierce the trabecular plate; i.e. no alicochlear commissures"

"the internal carotid arteries enter the cranial cavity directly" "no mesethmoid bone is developed (feature shared by certain placentals)"

"no ethmoidal cells or sinuses are excavated (except in Phascolarctos)" "the premaxillae bear a dentinal egg-tooth..."

"The characteristic features of the developing marsupial skull apart from those shared with monotremes (see above) and with placentals (see below)... are not clear cut" ([1]:466):

"The presence of two pairs of hypoglossal foramina (feature shared with some rodents and Sirenia)"

"The presence of a foramen rotundum between the ala temporalis and processus ascendens (feature not present in Didelphis, Dasyurus; shared with some Carnivora and Primates)"

"The loss of the pila metoptica"

"The diagonal position of the plane of the foramen olfactorium"

"The small size of the frontals"

"The large size of the lachrymals"

"The great length of the jugals"

"The poor development of the palatine process of the maxillae"

"The extension of the alisphenoid to form a bulla surrounding the tympanic cavity"

"The inflection of the posterior angle of the dentary"

"The outer bar to Jacobson's capsule (shared by Dasypus, Tupaia, Macroscelides, Chrysochloris, Orycteropus)"

"The papillary cartilage (shared with Tupaia, Macroscelides, Miniopterus and some Rodentia)"

"... features shared by marsupials and placentals..." ([1]:466):

"The subdivision of the foramen olfactorium advehens to form the cribiform plate"

"The substitution of the fenestra rotunda and aqueductus cochleae for the foramen perilymphaticum"

"The presence of a crista semicircularis in the nasal capsule"

"The loss of the pila antotica"

"The loss of the septomaxilla (except in the Xenarthra)"

"The fusion of the reptilian pterygoid (secondary pterygoid cartilage) with the lateral wing of the parasphenoid"

"The fusion of the cartilaginous elements of the $2^{\text {nd }}$ and $3^{\text {rd }}$ branchial arches to form thyroid cartilages"

[42, 147]. The incus is mobile relative to the cranium and functions as a jaw joint until the resorption of Meckel's cartilage [132]. The resorption of Meckel's cartilage [148] occurs postnatally and results in the definitive separation and differentiation of the malleus [141] (Fig. 22). 
Table 3 Features of the ethmoidal region hypothesized to be part of the marsupial "Grundplan" by Freyer [94], based on her critical assessment of ontogenetic and comparative anatomical data of the group

A rostrally wide closed cupula nasi anterior

A short processus cupularis

The processus laterales ventrales continuously connected to the lower edge of the septum and a caudal transition into the lamina transversalis anterior

A processus alaris superior supporting the sulcus alaris with its dorsolateral lamella

Lack of a commissura alicupularis - no connection between the processus cupularis and the processus alaris superior

An inferior septal ride

A superior septal ride

A spina mesethmoidalis

Lack of a fenestra internasalis (unfenestrated septum nasi)

A cartilago papillae palatinae

A rostral zona anularis

An incisura nasopalatina

A rostral process starting from the medial coiling of the lamina transversalis anterior, which corresponds to the dorsal lamella of the cartilago paraseptalis

Location of the lamina transversalis anterior on the same horizontal plane as the lower edge of the septum nasi (a "keel" is absent)

A ridge process (sensu [49]), a process of the lamina transversalis anterior

A fibula reuniens, dorsally framing the opening of the Jacobson's organ The cartilago paraseptalis not closed to form a tube

A fissura septoparaseptalis running along the whole extent of the cartilago parasetalis

A medial separation of the cartilago paraseptales

The Jacobson's organ opening into the nasal opening section of the ductus nasopalatinus, there is a communicative connection between the Jacobson's organ, the ductus nasopalatinus and the cavum nasi Opening of the Jacobson's organ lies at its rostral pole (lack of a process rostral of the opening)

A lamina transversalis posterior

A caudal zona anularis

A caudally closed cupula nasi posterior

A marginoturbinale

An atrioturbinale

A processus posterior atrioturbinalis

An incisura maxillo-atrioturbunalis

A maxilloturbinale

A processus anterior maxilloturbinalis

A lamellar nasoturbinale

A latero-medial glandular ridge is present, which stays separated from the superior septal ridge

Four ethmoturbinalia

An interturbinale between the 2. and 3. ethmoturbinale

Three frontoturbinalia

The processus uncinatus is connected to the paries and does not display a free process caudally

A wide commisura orbitonasalis has formed, which is connected to the paries

Ramírez-Chaves et al. [141] found that "middle ear detachment" (i.e., the disappearance of Meckel's groove) is allometric, occurring earlier in smaller species and later in larger ones. The relation of the middle ear to the size of the mandible during ontogeny has been generally assumed to be negatively allometric [59]. Ramírez-Chaves et al. [141] found that this kind of proportion exists only after ossification of the ossicles has been nearly completed.

\section{Tegmen tympani}

The tegmen tympani is a process or "wing", initially formed in cartilage, that originates in continuity with the anterolateral part of the pars canalicularis of the auditory capsule [8, 149]. Originally named by Hyrtl [150], it forms part of the caudal roof of the tympanic cavity, where it is crossed by the facial sulcus $[1,8]$.

The tegmen tympani has been regarded as a neomorphic feature of therians [25, 74]. Rougier et al. [151] hypothesized that this feature is present in Vincelestes, a stem therian from the Early Cretaceous of Argentina. In marsupials, the tegmen tympani is a rudimentary structure and is somewhat inconspicuous in the adult (e.g., $[1,41,45,53,55,66$, 126]). According to Van Kampen's ([25]:345) comment on the subject, in marsupials and bats the anterior part of the tegmen tympani is highly variable and often missing ("Der vordere Teil des Tegmen tympani ist sehr veränderlich und fehlt nicht selten ganz"). This has been misinterpreted as meaning that the entire structure is absent in marsupials. Clearly, however, Van Kampen [25] described its presence and condition in several marsupials, including didelphids ([25]:398; regarding Didelphis marsupialis, see Toeplitz [53] and de Beer [1]:301, but see also Aplin [66]), peramelids ([25]:401), phascolarctids ([25]:407), and macropodids ([25]:414). More recently, an incipient tegmen tympani has also been noted for the young of Thylogale [42], Phalanger [152], Cercartetus [66] and Macropus [62, 66]. We report here a small tegmen tympani restricted to the rear of the roof of the epitympanic recess in Macropus eugenii (Figs. 13d and 14a). In the specimen studied, the ossification process has started on the lateral part of the commissura suprafacialis and the adjacent part of the pars canalicularis. The tegmen tympani is continuous with both of these structures. Schmelzle [62] (page 49, fig. 51), named this ossifying area in Macropus eugenii the "commissura suprafacialis lateralis", formed by replacement (one with a cartilaginous precursor) and appositional bone ("Zuwachsknöcherung"), but for clarity it is important to note that the commissura suprafacialis lateralis is structurally continuous with the tegmen tympani. Additionally, the ridge that he called the "processus epitympanicus cochleae" ([62]:22) appears to merely be the lateral edge of the commissura suprafacialis and does not require a separate name. In addition, Schmelzle [62] recorded differences in the ossification mode of the tegmen tympani in various species, but these do not affect the homology of the structures concerned.

Aplin [66] discussed the tegmen tympani critically with new information on several species. Aplin ([66]:6-37) reported that in pouch young of Macropus and Cercartetus "a fibrous, fascial membrane", which we identified as the membrana epitympanica (see below), roofs over the auditory ossicles. He noted that the membrane contains a "nodular piece of cartilage" maturing later than the surrounding skeletal structures and which he identified as 


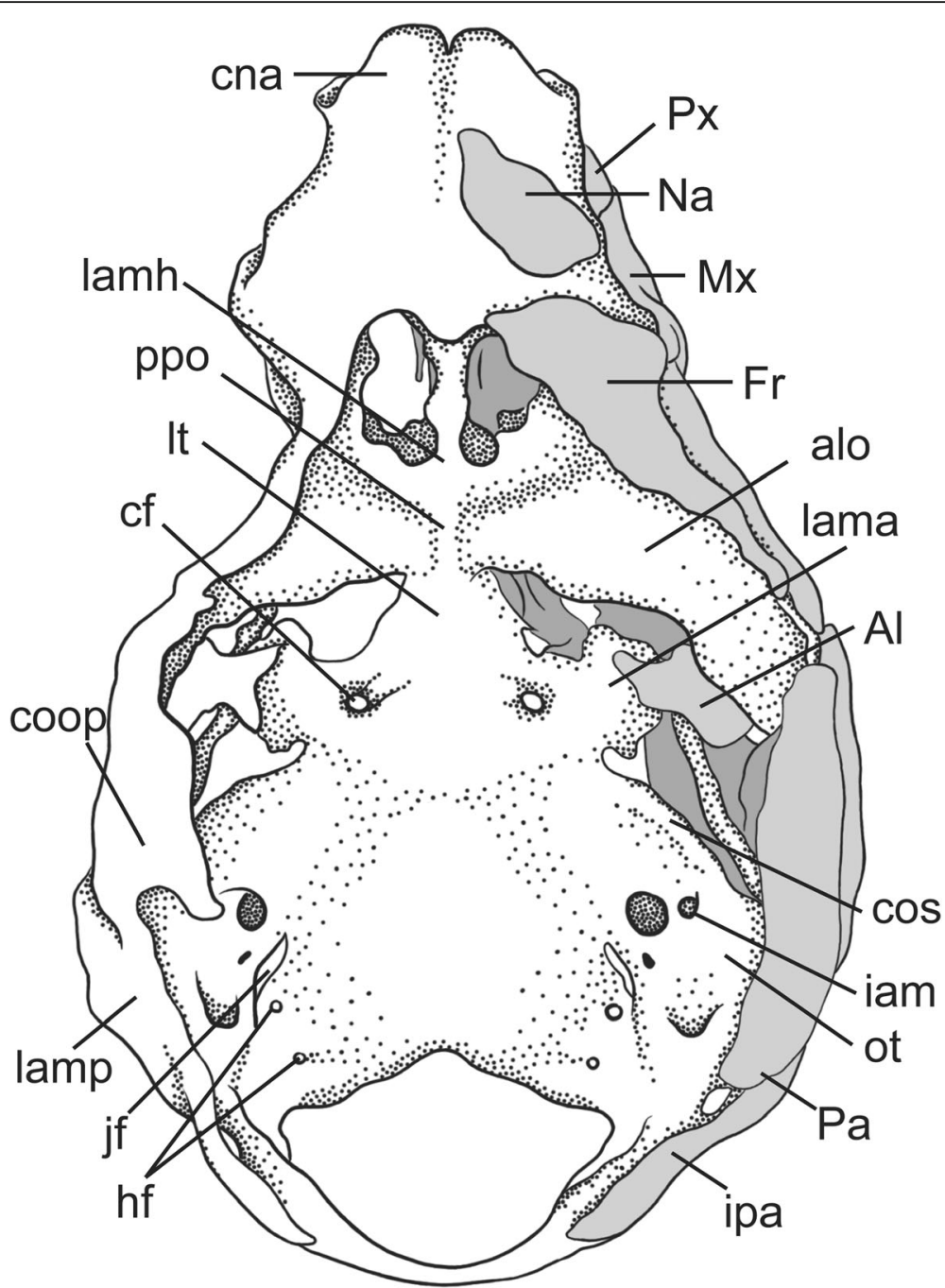

Fig. 17 Dorsal view of the chondrocranium of a diprotodontian marsupial, the wallaby Wallabia rufogrisea (CRL 37 mm) modified from Müller [61]. On the right side, depicted also the dermal bones documented at this stage

the tegmen tympani. However, this is unlikely since the tegmen tympani has never been seen to originate as an independent element in other mammals. It may be that the nodular piece of cartilage is related to structures occasionally seen in many mammals in this area of the developing skull of (e.g., the element of Paaw: the tendon of the stapedius muscle, Fig. 15a; the element of Spence: a skeletal element associated with the chorda tympani; [8]). In this context also, for Trichosurus vulpecula Broom [51] named a cartilaginous ridge projecting downwards from the otic capsule and apparently separated from it, which he identified as the tegmen tympani. As illustrated ([51]:fig. 22), this interpretation cannot be correct. The ridge is either Reichert's cartilage (second pharyngeal arch) or, as Broom himself noted ([51]:201), possibly a projecting part of the exoccipital.
In the macerated skull of Monodelphis brevicaudata, the tegmen tympani is seen as a small process, lateral to the facial nerve. This structure has sometimes been identified as the tuberculum tympani, but it is the precise equivalent of the tegmen tympani of placentals ([30]:160, fig. 7).

It seems that for marsupials detailed studies of finegrained ontogenetic series are necessary to establish the nature of the small processes and structures in the area identified as tegmen tympani. Although such detailed comparative anatomical research is relevant, it is unlikely to provide significant results in the form of well constrained systematic characters. At microscopic scale, there is proved to be much diversity in the extent of structures and their mode of ossification. Trying to incorporate such details into character definition for phylogenetic analysis is likely to be unfruitful [153]. 


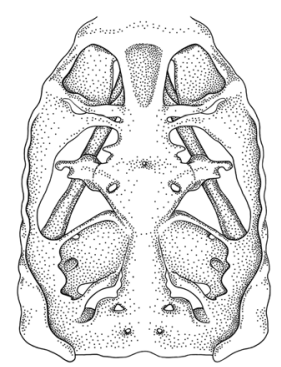

Monodelphis PND0
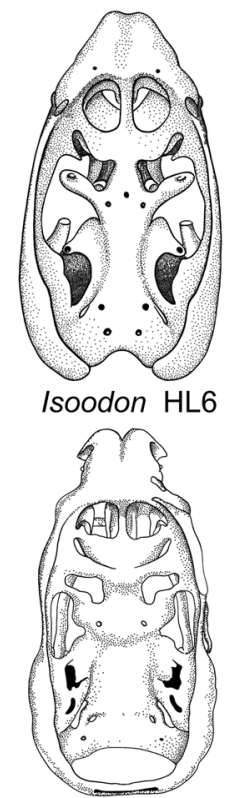

Dasyurus CRL9.3

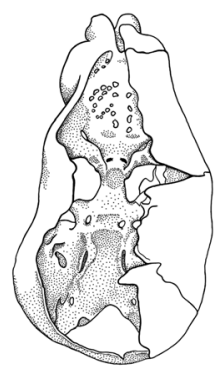

Didelphis CRL45.5

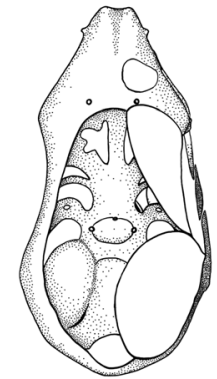

Perameles HL11

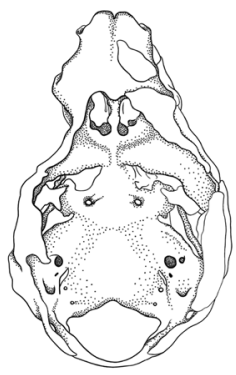

Wallabia CRL37
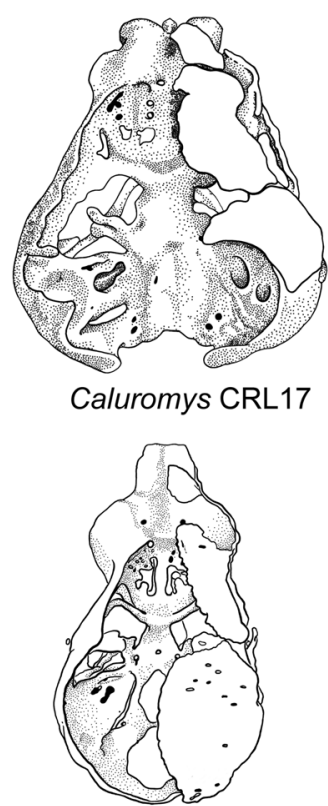

Perameles HL18.5

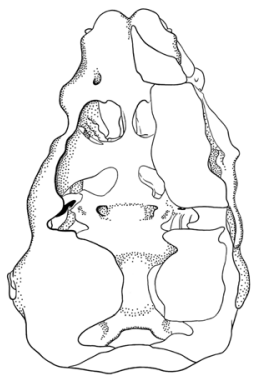

Vombatus HL14

Fig. 18 Dorsal view of chondrocrania of marsupials at different stages of development. On the right side, depicted also the dermal bones documented at the respective stage. Drawings were modified from the cited sources. Measurements are in millimeters. Depicted are models of the short-tailed opossum Monodelphis domestica by Maier [57], the opossum Didelphis marsupialis by Toeplitz [53], the bare-tailed woolly opossum Caluromys philander by Denison and Terry [54], the short nose bandicoot Isoodon obesulus by Esdaile [56], the long-nosed bandicoot Perameles nasuta by Cords [55], the eastern quoll Dasyurus viverrinus by Broom [51], the wombat Vombatus ursinus by Klutzny [60], and the wallaby Wallabia rufogrisea by Müller [61]

\section{Tympanic cavity and tympanic floor soft tissues and bony elements}

The cavum tympani is a mucous-membrane lined space that fills the osseous middle ear cavity and into which the auditory ossicles project [8]. During ontogeny, the cavum tympani expands. As it does, the mucoid tissue filling the cavity is resorbed until the cavum attains the middle ear limits. In the embryo, these limits are defined by membranes; the membrana epitympanica at the roof, the fibrous membrane at the floor, and the tympanic membrane (=eardrum). The definitive tympanic cavity (=middle ear cavity) is the osseous chamber containing the cavum tympani [8]. The tympanic cavity can also include the pneumatization from the surrounding basicranial elements [73].

The proliferation of cells within the mesenchyme surrounding the expanding cavum tympani forms the fibrous membrane of the tympanic cavity [8], which is continuous with other connective tissue lining the basicranium (including the tissues of the membranous meatus in Figs. 6e, f, 11f and 13b). Cartilaginous or bony auditory bulla elements will later develop within this membrane or adjacent to it [74]. This tympanic floor also separates the tympanic space and contents from surrounding structure. In the adult it can be membranous, or consist of cartilaginous and/or bony structures. In adult marsupials, as many as three bones can form the tympanic floor; the alisphenoid (alisphenoid tympanic process), the ectotympanic and the petrosal (rostral and caudal tympanic processes petrosal; RTPP and CTPP, respectively) (e.g., [78, 98, 154158]). The possible presence of an entotympanic, as a fourth bone in the tympanic floor, is discussed below.

A membranous bulla forming the tympanic floor is interpreted as the plesiomorphic condition for marsupials, as no bony floor is present in most Mesozoic and 


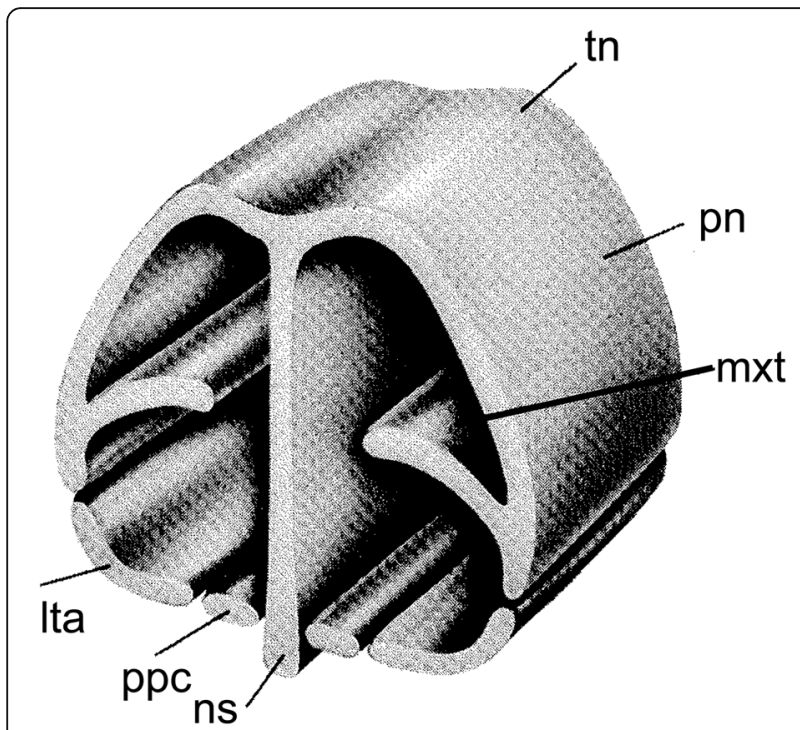

Fig. 19 General schematic view of the anterior part of the nasal chondrocranium indicating its major features. Modified from Klima [216]
Cenozoic stem metatherian species (e.g., [29, 101, 103, 159-161]). There are however some exceptions (e.g., Asiatherium and herpetotheriids, probably the sistergroup of crown marsupials [162]) that did have an alisphenoid bulla $[162,163]$. Although classically considered to be a marsupial autapomorphy (e.g., [73, 157, 164]), the presence of an alisphenoid contribution to the floor of the tympanic cavity is a derived state that occurred independently in different metatherian lineages $[14,34,103,158$, $162,163]$. As is usually the case with tympanic floor components other than the ectotympanic, the formation of the alisphenoid tympanic process appears to be a late event (e.g., in Monodelphis domestica it happens around PND-35, only 15-20 days before weaning [165]).

Bullar ontogeny has been documented for several marsupials (e.g., Monodelphis domestica, Didelphis marsupialis, Caluromys philander, Perameles nasuta and Isoodon obesulus, Dasyurus viverrinus, Vombatus ursinus and Macropus eugenii [9, 41, 53-57, 60, 62, 66]). Additional information from macerated skulls, presented in an ontogenetic perspective by Maier [31] has been gathered for six didelphids, one dasyurid and two diprotodontians.

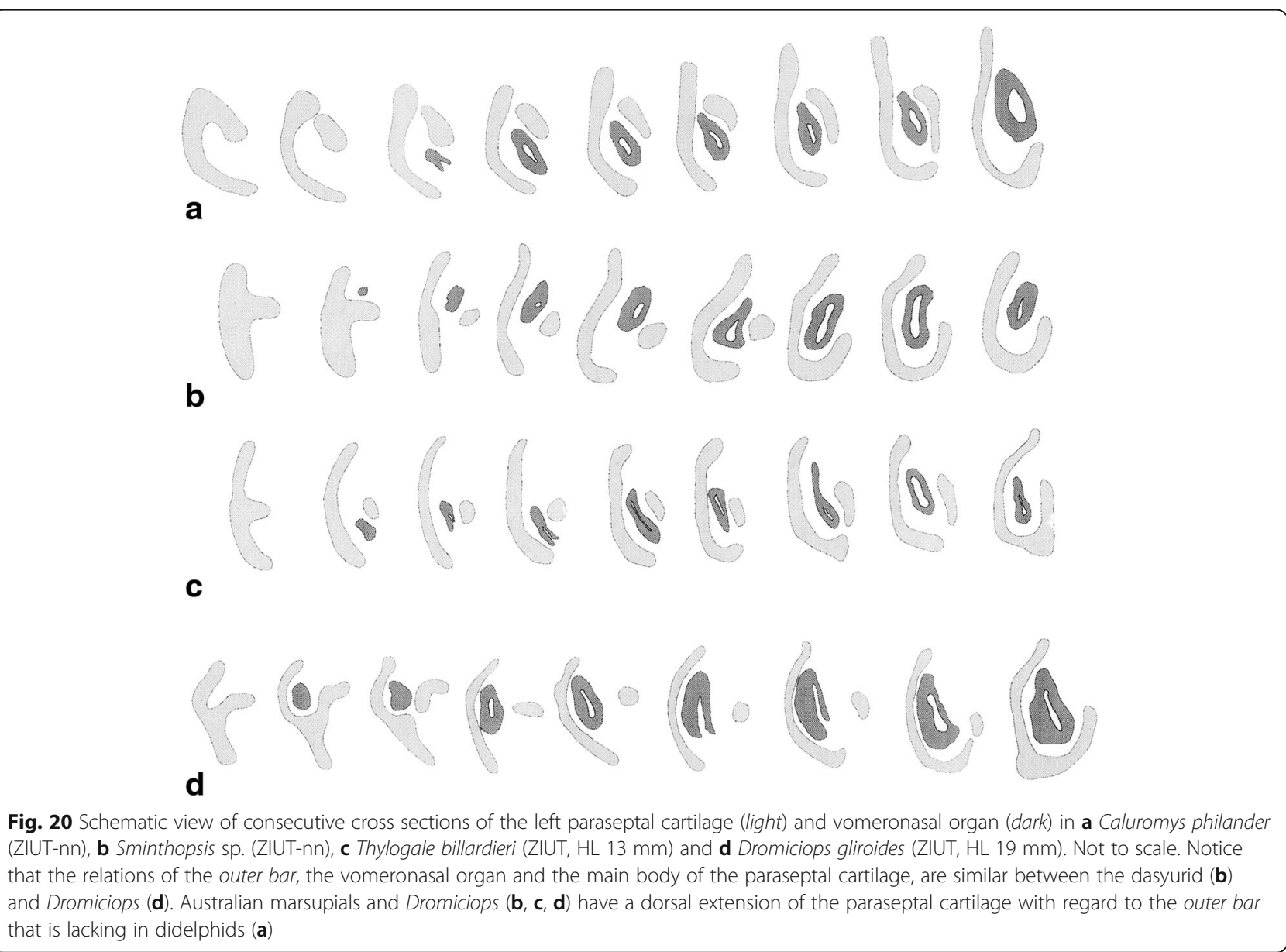




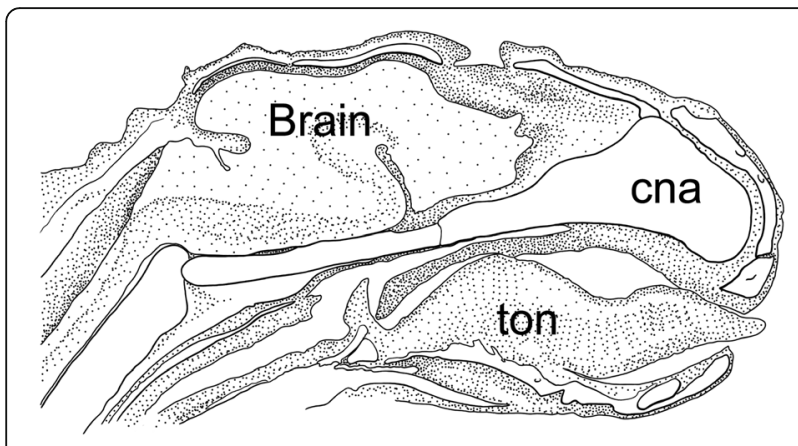

Fig. 21 A schematic sagittal section serves to illustrate the whole of the head at postnatal age 1-day in the opossum Monodelphis domestica (drawing based on photograph published by Maier [75], p.62). The epiglottis reaches the dorsal side of the velum. Notice the lack of a chondocranial coverage of the dorsal brain, present in monotremes $[12,45]$

The entotympanics represent an "assortment of nonhomologous entities" [166-168], that are "bony or cartilagenous, that lie in the ventral wall of the tympanic cavity and are ontogenetically primarily independent of the other elements in the auditory bulla, except perhaps the tympanohyal and the cartilage of the Eustachian tube [= tubal cartilage]" $[8,26,166,168-174]$. Following van der Klaauw [26, 169], two types of entotympanics are distinguished based on their approximate site of formation: rostral and caudal. The rostral entotympanic most commonly develops in close relation to the tubal cartilage and is primordially continuous with it (e.g., in the vespertilionid bat Miniopterus, as described by Fawcett [175]; Elephantulus fuscipes, [8]). The caudal entotympanic appears in the rear part of the tympanic floor, sometimes but not always in relation to Reichert's cartilage. It extends between the ectotympanic and the petrosal.

Entotympanics have figured prominently in many discussions of mammalian systematics [168]. Many authors have pointed out that entotympanics have no evident homologues among non-eutherian mammals or other tetrapods and are placental neomorphs ([27]; [166]:38; [17, 168]). However, numerous reports of entotympanics in marsupials exist in the literature (see Maier [31] for a review). Parker ([69] cited in Winge [27]:122) noted that many marsupials have what he called "Os bullae" (=entotympanics). Carlsson [176] and Wood-Jones [177] reported an entotympanic in the dasyurid Dasycercus spp., as Van der Klaauw [26] did for Perameles sp. and Vombatus sp., and Segall [154-156, 178]) reported its occurrence in Didelphis sp., Caluromys sp., Dactylopsila sp., Isoodon obesulus and (as in Hershkovitz [179]) Dromiciops gliroides. The presence of a septum inside the bullar wall ("septum sphenoideum") in a number of phalangeroid genera was cited by Segall [178] as the division between the tympanic process of the alisphenoid and the entotympanic. But none of these reports of entotympanics in
Table 4 Relations of the ala temporalis to the branches of the trigeminal nerve in several marsupials. Trichosurus A: "young". Trichosurus B: "older"

\begin{tabular}{|c|c|c|c|c|}
\hline Taxon & $\begin{array}{l}\text { Between } \\
\text { V1 \& V2 }\end{array}$ & $\begin{array}{l}\text { V2 traverses } \\
\text { ala temporalis }\end{array}$ & $\begin{array}{l}\text { Between } \\
\text { V2 \& V3 }\end{array}$ & Source \\
\hline \multicolumn{5}{|l|}{ Didelphidae } \\
\hline Monodelphis & $x$ & & & $\begin{array}{l}\text { Maier, } 1987 \text { [57] } \\
\text { Sánchez-Villagra } \\
1998 \text { [65] }\end{array}$ \\
\hline Didelphis & $x$ & & & $\begin{array}{l}\text { Fuchs, } 1915 \text { [208] } \\
\text { Presley, } 1981 \text { [78] } \\
\text { Maier, } 1987 \text { [57] }\end{array}$ \\
\hline Philander & $x$ & & & Maier, 1987 [57] \\
\hline Caluromys & $x$ & & & Maier, 1987 [57] \\
\hline \multicolumn{5}{|l|}{ Dasyuridae } \\
\hline Sminthopsis & & $x$ & & Maier, 1987 [57] \\
\hline Dasyurus & & & $x$ & $\begin{array}{l}\text { Broom, } 1909 \text { [51] } \\
\text { Maier, } 1987 \text { [57] }\end{array}$ \\
\hline
\end{tabular}

Peramelidae

\begin{tabular}{|c|c|c|}
\hline Perameles & ?X & Maier, 1987 [57] \\
\hline Isoodon & $x$ & $\begin{array}{l}\text { Esdaile, } 1916 \text { [56] } \\
\text { Maier, } 1987 \text { [57] }\end{array}$ \\
\hline
\end{tabular}

Phalangeridae

Trichosurus A $x$

de Beer, 1926 [209] Goodrich, 1930 [210] Sánchez-Villagra 1998 [65]

Trichosurus B

X Broom, 1909 [51] Maier, 1987 [57]

Petauridae

Petaurus

Macropodidae

Petrogale

Wallabia

X This work

Acrobatidae

Acrobates

Vombatidae

Vombatus

$x$

Klutzny, 1994

[60]

Sánchez-Villagra 1998 [65]

marsupials have been substantiated with detailed descriptions of adult skulls or developmental data. Archer [29] did not find entotympanics in his exhaustive review of the (adult) marsupial basicranium.

Examination of dozens of macerated skulls of Didelphis spp. revealed that what Segall [178] called an entotympanic in this species is actually the RTPP, the pars petrosa of Patterson ([180]) [65]. Also, there is no conclusive evidence of an entotympanic in Dactylopsila sp. (DUCEC- 

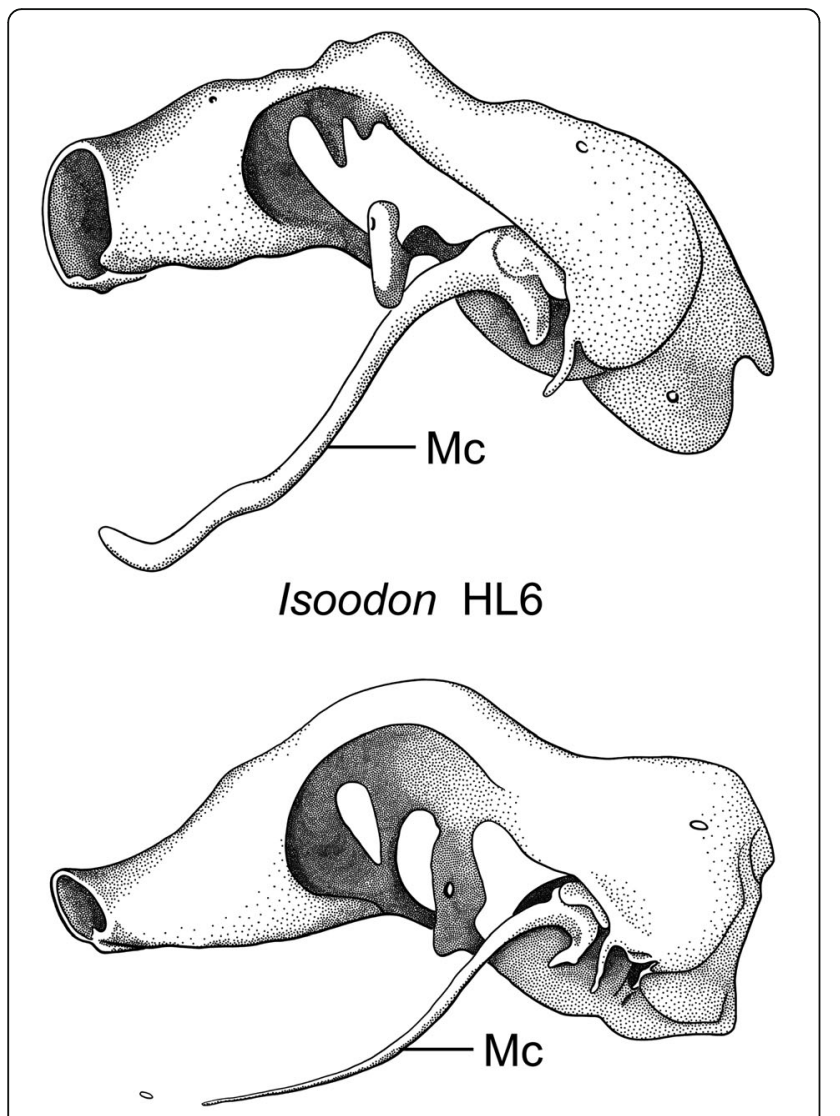

Perameles HL11

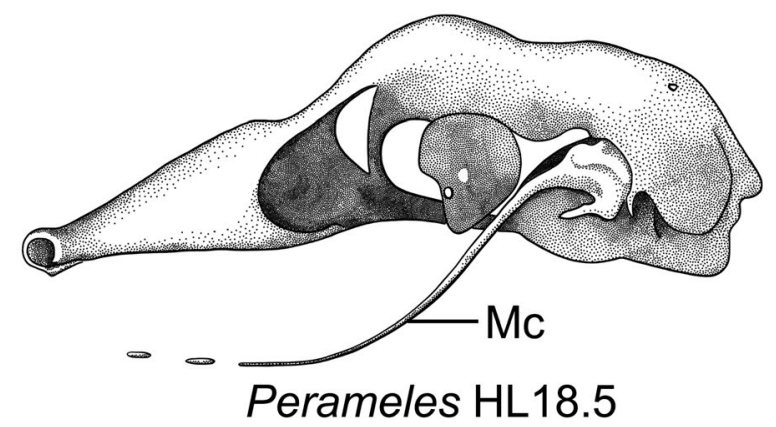

Fig. 22 Left side of chondrocranium, without membrane bones, in bandicoots (Peramelemorphia) at different stages of development. Cardboard reconstructions, modified from Esdaile [56]. Top, cf. Isoodon obesulus, Perameles obesula in the original paper, Stage II. TL $15.5 \mathrm{~mm}$. HL 6.0 mm (× 25.); middle, Perameles nasuta, Stage IV. TL 23.0 mm. HL $11.0 \mathrm{~mm}$ (× 12.); bottom, Perameles nasuta, Stage V. TL $35.0 \mathrm{~mm}$. HL $18.5 \mathrm{~mm}(\times 7$.

8323), contra Segall ([156]: 197; [178]: 27, 41, 42). Dactylopsila sp. has the typical bullar condition of most diprotodontians, consisting of a squamosal roof of the middle ear, and a squamosal process contributing to the lateral side of the bulla overlain medially in part by a tympanic process of the alisphenoid (DUCEC-8323, Fig. 23). This condition was labeled as "partially bilaminar" by Murray et al. [32] and can be discerned only by looking at sectioned material. In the extinct vombatiform Wakaleo vanderleuri this condition becomes more accentuated in that the squamosal fully surrounds the middle ear cavity [32]. This greater contribution of the squamosal characterizes wombats, which in addition show almost no remnant of an alisphenoid tympanic process [28].

Presley [181] described an "entotympanic-like" element in Trichosurus vulpecula, which he attributed to an early contact between Reichert's cartilage and the auditory capsule, but he was referring actually to the RTPP $[8,67]$. Presley [182] also described this contact between Reichert's cartilage and the cochlear capsule in Didelphis, but Maier ([31, 41]) found no evidence of such contact in the close relative Monodelphis and in other marsupials. In all cases, the RTPP was formed by periosteal outgrowth from the ossifying cochlear capsule (Maier [31, 41]), as described for the RTPP in a variety of placentals [8]. The only two well-substantiated reports of entotympanics in marsupials deserve discussion.

Norris [183] studied macerated skulls of different ages of Phalanger orientalis and found that the bulla remained membranous even at the stage when the third molar erupted. He recorded three areas of incipient ossification; the first two are in the alisphenoid. The third and caudalmost ossification is described as an element within the bullar membrane independent of any of the surrounding bones; it is therefore (according to Norris) an entotympanic. Norris [183] reported that by the time the fourth molar erupts, the rapid ossification of these centers obliterated any sign of independent ossifications in the floor of the bulla.

Aplin ([66]:5-25) mantained, on the basis of a study of macerated ear regions of Acrobates and cranial sections of a pouch-young Distoechurus, that the anterior bullar element of these species is an intramembraneous ossification "quite distinct from the cartilage of the auditory tube", which he referred to as an entotympanic. As described by Aplin [66], this element corresponds to the rostral entotympanic of some placentals. However, the typical placental rostral entotympanic forms initially in cartilage and chondrifies in direct continuity with the tubal element (some exceptions in Wible and Martin [184]), whereas the nature of the element in acrobatids seems quite distinct. Such differences aside, the anterior bullar element of acrobatids might represent the first (and only) independent intramembraneous entotympanics-like element to be reported in any marsupial [66].

The basicranium of Dromiciops is of particular interest. It had been studied by Segall [154] through examination of macerated skulls of adults. We examined histological sections of a juvenile of $\mathrm{CRL}=$ 


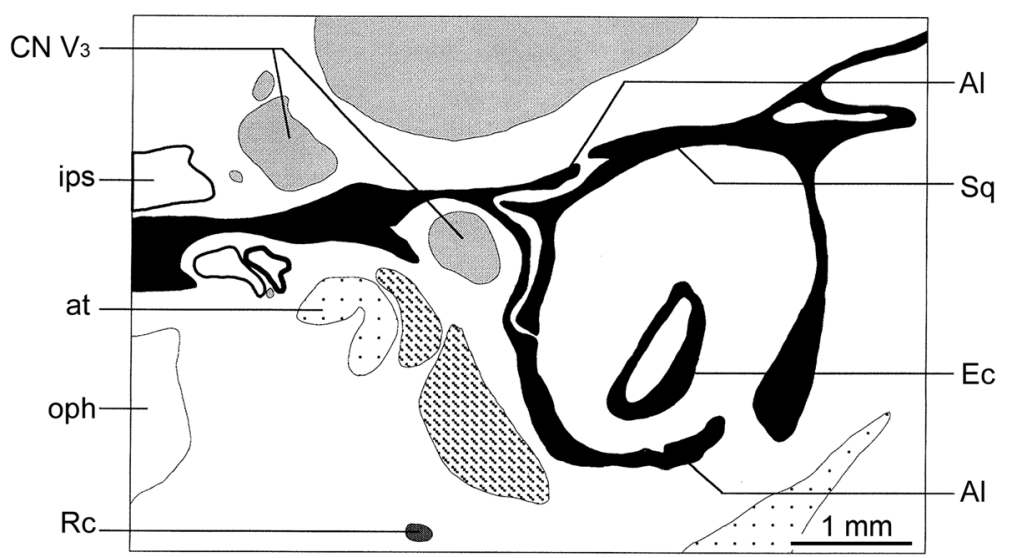

Fig. 23 Schematic drawing of the cross section of the basicranium of Dactylopsila sp. (DUCEC-8323, section 1313 Plate 6a). This species exhibits the typical bullar condition of most diprotodontians, consisting of a squamosal roof of the middle ear, and a squamosal process contributing to the lateral side of the bulla overlain medially in part by a tympanic process of the alisphenoid

$37 \mathrm{~mm}$ (ZIUT, HL $19 \mathrm{~mm}$ ) (Figs. 6, 7, 8, 9 and 10), see also Sánchez-Villagra and Wible [98]. In spite of the fairly advanced state of ossification of this specimen, the high resolution of the sectioned material allows a rejection of the specific interpretations of Segall [154] and Hershkovitz [179] about the possibility of an entotympanic in Dromiciops (lack of an entotympanic was reported but not documented by Maier [31]). This conclusion is reached in conjunction with observations of dozens of macerated skulls of adults at the Field Museum of Natural History [65]. As identified by Sánchez-Villagra and Wible ([98], fig. 11) in a macerated skull, the auditory bulla of Dromiciops is clearly formed by three components: (1) the anteriormost element is the tympanic process of the alisphenoid (Fig. 6), (2) the middle element is the RTPP (Fig. 8), and (3) the posterior element is the CTPP, with a medial prong projecting anteriorly.

In Dromiciops, the ectotympanic forms a nearly complete ring inside the bulla (in an aphaneric [not visible from the external surface] position), and does not contribute to the bulla in ventral view. As described by Hershkovitz [179]) and also recorded here, the basioccipital expands laterally to overlap (partially cover) the medial side of the bulla. Accordingly, two layers of bone are present in this area: the medial bullar compartment and the basioccipital ventral to it. Even though they did not provide developmental data to support their claims, other authors have correctly assessed the bullar composition in Dromiciops. Reig and Simpson ([185]:525) named the medial compartment as "pars petrosa", while Szalay ([17]:75) called it the "petrosal wing" (= RTPP of this work; Fig. 8b-d). The posterior compartment was named "pars mastoidea" (= CTPP; Fig. 10b) by Reig and Simpson ([185]:525) as well as Patterson [180].
A similar condition to that of Dromiciops with respect to bullar composition is found in the honey possum Tarsipes. The latter exhibits a complete tympanic floor formed by an alisphenoid tympanic process, and conjoined RTPP and CTPP ([66]:6-30).

In summary, no conclusive evidence of entotympanic bones was found in the tympanic floor of the marsupials examined. So far, this element has been considered a derived feature of placentals $[165,167]$. The report of an entotympanic-like element in acrobatids [66] deserves further examination. Additionally, if an "entotympanic" element is present in the bulla of some Phalanger orientalis [183], this would add to the striking variability of bullar makeup in this species. We describe here the tubal element of Dromiciops (Fig. 7), because its histological nature resembles that of some placental taxa in which the rostral entotympanic forms in continuity with the tubal cartilage (e.g., Elephantulus [8]).

\section{Auditory tube and tubal element}

The tubotympanic recess, a derivative of the first pharyngeal pouch [186], differentiates to become the tympanic cavity of the middle ear and the auditory tube. The auditory tube (=Eustachian or pharyngotympanic tube) is the channel of communication between the tympanic cavity and the nasopharynx that mediates pressure within the middle ear. Surrounding the auditory tube in some species is a differentiated cartilaginous auditory tube (CAT) or "tubal element", most frequently described for placentals (e.g., [8]) and in the echidna, but not in the platypus $[9,187,188]$. Reports of cartilage in marsupials are contradictory [65].

In relation to the nature of the tubal element in marsupials, Wible ([9]:298) stated: "a cartilage of the 
auditory tube reaches medially from the anterolateral corner of the promontorium's anterior pole and shields the rostral surface of the auditory tube in its passage to the pharynx in the developmentally older pouch young Perameles nasuta (HL-H Ms235) and Macropus rufogriseus [his "Wallabia rufogrisea"] (AIF 7895) (figs. XI-7, XI-9). This element does not, at least in the forms investigated, contribute to the tympanic roof. To my knowledge, this is the first account of the cartilage of the auditory tube in marsupials". This observation by Wible ([9]; see also Weber [188] and Edgeworth [189]) contrasts with the report by Maier et al. ([187]: 16) that "the auditory tube of didelphids (and possibly of all marsupials) is not framed by tubal cartilages, but only by dense connective tissue".

Sucheston and Cannon [190] reported a fibrous/collagenous tubal element without hyaline cartilaginous tissue in an adult opossum Didelphis marsupialis, as part of an extensive histological study including eight placental species, for which they described several kinds of cartilage in the tubal element. Similarly, Aplin [66] reported a fibrous/collagenous tubal element in all but one diprotodontian marsupial of his extensive histological sampling of this group. In addition, Aplin [66] recorded in an adult of the honey possum Tarsipes a large tubal element containing chondrocytes, with the element serving as a major source of origin of the medial pterygoid muscle.

In terms of the specimens examined in this work, we report that the tubal element in most marsupials consists of mesenchymal tissue that resembles precartilaginous tissue, but no cartilage per se was seen (Figs. 4b, 11c, d and 13b). A reexamination of the specimen of Macropus rufogriseus that was described by Wible [9] as having a tubal cartilage may be in fact consist of dense connective tissue characterized by the proliferation of cell nuclei, but lacking chondrocytes or cartilaginous matrix ZIUT-nn, [65]: section 41-2-2; Figure IV-2a). In this case, an examination of developmental series that include relatively late stages will be needed to best characterize the tissues in question.

In Dromiciops the tubal element is definitely best described as a type of cartilage with high fiber content (Fig. 7). Whether it corresponds to the kind of fibrocartilage said to form the cartilage of the auditory tube in humans would have to be determined histochemically. As Ross et al. ([191]: 135) noted, "it is often difficult to distinguish fibrocartilage from dense regular connective tissue, particularly in hematoxylin and eosin stained sections". Fibrocartilage is typically in places where tendons attach to bones, indicating that "resistence to both compression and shear forces is required of the tissue" ([191]:136; see Kummer [192]). In the specimens examined, including Dromiciops, the tensor veli palatini muscle is attached to the tubal element (Fig. 7a), as was reported by Aplin [66] for many diprotodontians and as is the case in humans [193]. Some of the histological characteristics of the marsupial tubal element are reminiscent of fibrocartilage, perhaps because of the mechanical requirements of that tissue, though it is only a matter of speculation what forces are produced by the tensor veli palatini muscle.

The appearance of the tubal element occurs late in placental ontogeny relative to overall chondocranial development. Proctor [194] reported that in humans the cartilage forming the tubal element appears during the fourth month of fetal life. Many perinatal specimens of marsupials show dense connective tissue in the shape of what would be the CAT in placentals, but this tissue has not seen to differentiate any further in marsupials.

The lack of any kind of cartilagenous element in didelphids and most other marsupials with the exception of Dromiciops and Tarsipes cannot be interpreted with certainty as primitive or derived. The cartilage of placentals might be homologous to an ancestral mammalian condition if present in the echidna and secondarily lost in the platypus. If the ancestral therian had a cartilaginous tubal element, then the lack of cartilage in marsupials may be the result of truncation in the process of cartilage formation.

\section{Conclusions and looking ahead}

The study of histological sections is very time consuming and only the collections of extensive series is likely to deliver information that can serve to diagnose groups of organisms. This kind of work has been accomplished recently, principally by W. Maier, I. Ruf and colleagues in the examination of particular features (e.g., the chorda tympani, entotympanics) across groups of placental mammals, while discovering diagnostic features for several clades $[10,195]$. Indeed, variation in chondrocranial structures is a potential source of characters for phylogenetic analyses $[89,90]$. This has been barely explored in marsupials, with a few features restricted to the vomeronasal region [48, 102]. In fact, chondrocranial structures are indeed of almost no relevance in vertebrate cladistics (but see Haas [196] for a notable example). This is not surprising, as the intellectual traditions that produce these studies are quite different. The large number of discrete characters, as well as disparity in shape [197] could make the chondrocranium a source of characters for phylogenetic analyses of marsupials, but more studies and an assessment of intraspecific variation are needed. Studies of turtles, even if limited in the taxonomic scope examined, have proved to be original and worthwhile in this regard [198, 199]. Likewise, chondrocranial features and proportions have been used in discussions on the systematic allocation of vertebrate taxa (e.g., [200]).

A utilitarian argument for the study of the chondrocranium from the point of view of systematics is weak, 
as new diagnostic features are not likely to solve phylogenetic controversies and even the most consistent and unique of characters-should it exist, although the evidence speaks against that expectation-would be a modest part of a large data matrix of molecular data and of more easily obtained osteological and soft-tissue (e.g., myological) data. Guillerme and Cooper [201] have shown how a great number of mammalian groups are unstudied at the morphological level, and that this represents a hindrance to the incorporation of palaeontological data in systematic studies [202]. The knowledge of the chondrocranium is restricted to extant forms, as this is not preserved in fossils, however crucial to understand homologies. In summary, the study of the chondrocranium can be driven by an interest in the evolution of form and function. This needs as much or as little justification as any other intellectual pursuit.

Several authors ([1, 42, 57, 71]:165) have pointed out how some aspects of the anatomy of the chondrocranium could have functional significance for the embryo in the early postnatal life of marsupials. The area which has attracted the most attention in terms of functional morphology is that concerned with the origin of the middle ear and the transformation in the masticatory apparatus [203]. The quantification of changes in the structures involved and their spatial relations is a first step to address this subject [141], which at this point requires biomechanical studies. In this regard, how the shape of the anterior chondrocranium differs between marsupials and placentals, and among mammals of different levels of altriciality and precocity, as discussed in this paper, is also a potential subject of investigation.

Any consideration of cranial biomechanics would have to consider the architecture of muscles [204]. Much of the differentiation of craniofacial muscles in marsupials is perinatal if not postnatal, especially so in the highly altricial dasyurids, in which the "jaw muscles at birth consist of little more tan a few myotubes" ([39], p. 1186). As documented in previous works and discussed by K.K. Smith [39], differences in the timing of maturation of branchial arch muscles and the suppresion of one generation of the dentition [205] in marsupials, which evolved convergently in several placental clades [206, 207], are also fundamental aspects to consider in seeking to understand the functional morphology of early postnatal life.

\footnotetext{
Acknowledgments

We thank Ross MacPhee for generously sharing many insights into specific aspects of cranial development and terminology as this manuscript was in preparation, Guillermo Rougier for many useful suggestions and corrections to the text, and two anonymous colleagues for useful reviews. Kathleen Smith povided generous mentoring to MRS-V during the portion of this work conducted at Duke University. MRS-V thanks Wolfgang Maier for the years of support, teaching and access to unique materials at the University of Tübingen, and for the kind and enriching interactions. Timea Bodogán (Zurich) produced the drawings of the chondocrania and Ingmar Werneburg (Tübingen) provided comments on an early version; Alexandra Wegmann
}

provided technical assistance. The study was funded by the SNF fund 31003A_149605 to M.R.S.-V. and by a 2015 seed-grant from the EPFL Leading House-Swiss Bilateral Programmes to both authors of this paper.

\section{Funding}

The study was funded by the SNF fund 31003A_149605 to M.R.S.-V. and by a 2015 seed-grant from the EPFL Leading House-Swiss Bilateral Programmes to both authors of this paper.

\section{Availability of data and materials}

Not applicable: Data sharing not applicable to this article as no datasets were generated or analysed during the current study.

\section{Authors' contributions}

Both authors collected data, conducted analyses and wrote the paper. Both authors read and approved the final manuscript.

\section{Competing interests}

The authors declare that they have no competing interests.

Consent for publication

Not applicable.

Ethics approval and consent to participate

Not applicable.

\section{Author details}

${ }^{1}$ Paläontologisches Institut und Museum der Universität Zürich, Karl Schmid Strasse 4, Zürich 8006, Switzerland. ${ }^{2}$ IANIGLA, CCT-CONICET Mendoza, Av. Ruiz Leal s/nº, Mendoza 5500, Argentina.

Received: 15 October 2016 Accepted: 7 February 2017

Published online: 12 February 2017

\section{References}

1. de Beer GR. The development of the vertebrate skull. Oxford: Clarendon; 1937. Reprint: University of Chicago Press, 1985.

2. Zollikofer CPE, de León MS P. Virtual reconstruction: a primer in computerassisted paleontology and biomedicine: Wiley-Interscience. 2005.

3. Diogo R, Pastor JF, Hartstone-Rose A, Muchlinski MN. Baby gorilla: photographic and descriptive atlas of skeleton, muscles and internal organs. Oxford: CRC Press; 2014.

4. Metscher BD. MicroCT for developmental biology: a versatile tool for highcontrast 3D imaging at histological resolutions. Dev Dyn. 2009;238:632-40.

5. Brocklehurst RJ, Crumpton N, Button E, Asher RJ. Jaw anatomy of Potamogale velox (Tenrecidae, Afrotheria) with a focus on cranial arteries and the coronoid canal in mammals. PeerJ. 2016:4:e1906.

6. Weisbecker $V$, Richards S, Norman J. Methods for inexpensive, nonintrusive detection of skeletal elements in small zoological specimens using microcomputed tomography. Herpetol Rev. 2009;40:165-8.

7. Gignac PM, Kley NJ, Clarke JA, Colbert MW, Morhardt AC, Cerio D, Cost IN, Cox PG, Daza JD, Early CM. Diffusible iodine-based contrast-enhanced computed tomography (diceCT): an emerging tool for rapid, high-resolution, 3-D imaging of metazoan soft tissues. J Anat. 2016;228:889-909.

8. MacPhee RDE. Auditory regions of primates and eutherian insectivores. Basel: S. Karger; 1981.

9. Wible JR. The ontogeny and phylogeny of the mammalian cranial arterial pattern [Ph.D. thesis]. Durham: Duke University; 1984

10. Ruf I, Frahnert S, Maier W. The chorda tympani and its significance for rodent phylogeny. Mamm Biol. 2009;74:100-13.

11. Macrini TE. Development of the ethmoid in Caluromys philander (Didelphidae, Marsupialia) with a discussion on the homology of the turbinal elements in marsupials. Anat Rec. 2014;297:2007-17.

12. Zeller U. Die Entwicklung und Morphologie des Schädels von Ornitorhynchus anatinus (Mammalia: Prototheria: Monotremata). Abh Senckenb Naturforsch Ges. 1989;545:1-188.

13. Hall BK. Bones and cartilage: developmental and evolutionary skeletal biology. Academic Press; 2005.

14. Rougier GW, Wible JR, Novacek MJ. Implications of Deltatheridium specimens for early marsupial history. Nature. 1998;396:459-63. 
15. Luo Z-X, Yuan C-X, Meng Q-J, Ji Q. A Jurassic eutherian mammal and divergence of marsupials and placentals. Nature. 2011;476:442-5.

16. Clemens WA. Marsupialia. In: Lillegraven JA, Kielan-Jaworowska Z, Clemens WA, editors. Mesozoic Mammals The First Two Thirds of Mammalian History. Berkeley: University of California Press; 1979. p. 192-220.

17. Szalay FS. Evolutionary History of the Marsupials and an Analysis of Osteological Characters. New York: Cambridge University Press; 1994.

18. Starck D. Lehrbuch der speziellen Zoologie. Band II: Wirbeltiere. Teil 5: Säugetiere. Jena: Gustav Fischer Verlag; 1995.

19. Ladevèze S, de Muizon C, Beck RM, Germain D, Cespedes-Paz R. Earliest evidence of mammalian social behaviour in the basal Tertiary of Bolivia. Nature. 2011;474:83-6.

20. Diogo R, Bello-Hellegouarch G, Kohlsdorf T, Esteve-Altava B, Molnar JL. Comparative myology and evolution of marsupials and other vertebrates, with notes on complexity, Bauplan, and "scala naturae". Anat Rec. 2016;299:1224-55.

21. Rowe TB. Coevolution of the mammalian middle ear and neocortex Science. 1996:273:651-4.

22. Keyte A, Smith KK. Heterochrony in somitogenesis rate in a model marsupial, Monodelphis domestica. Evol Dev. 2012;14:93-103.

23. Beiriger A, Sears KE. Cellular basis of differential limb growth in postnatal gray short-tailed opossums (Monodelphis domestica). J Exp Zool B. 2014;322:221-9.

24. Flower WH. An Introduction to the Osteology of the Mammalia. 3rd ed. London: Macmillan; 1885.

25. Van Kampen PN. Die Tympanalgegend des Säugetierschädels. Morphol Jahrb. 1905;34:1-722

26. Van der Klaauw CJ. On the auditory bulla in some fossil mammals, with a general introduction to this region of the skull. B Am Mus Nat Hist. 1931;62: $1-340$.

27. Winge $\mathrm{H}$. The interrelationships of the mammalian genera. Vol I. Monotremata, Marsupialia, Insectivora, Chiroptera, Edentata. Copenhagen: C. A. Reitzels Forlag; 1941.

28. Wegner RN. Der Schädel des Beutelbären (Phascolarctos cinereus Goldfuss 1819) und seine Umformung durch lufthaltige Nebenhöhlen. Abh Berlin. 1964;4:1-86

29. Archer M. The basicranial region of marsupicarnivores (Marsupialia), interrelationships of carnivorous marsupials, and affinities of the insectivorous marsupial peramelids. Zool J Linn Soc. 1976;59:217-322.

30. Wible JR. On the cranial osteology of the short-tailed opossum Monodelphis brevicaudata (Didelphidae, Marsupialia). Ann Carnegie Museum. 2003;72:137-202.

31. Maier W. Morphologische Untersuchungen am Mittelohr der Marsupialia. Z Zool Syst Evol. 1989;27:149-68.

32. Murray $P$, Wells R, Plane M. The cranium of the Miocene thylacoleonid, Wakaleo vanderleuri: click go the shears - a fresh bite at thylacoleonid systematics. In: Archer M, editor. Possums and Opossums: Studies in Evolution, Vol 2. Sydney: Surrey Beatty \& Sons: Chipping Norton; 1987. p. 433-66.

33. Springer MS, Woodburne MO. The distribution of some basicranial characters within the Marsupialia and a phylogeny of the Phalangeriformes. J Vertebr Paleontol. 1989:9:210-21.

34. Wroe S. A reexamination of proposed morphology-based synapomorphies of the families of Dasyuromorphia (Marsupialia). I Dasyuridae. 1997;4:19-52

35. Macrini TE. Comparative morphology of the internal nasal skeleton of adult marsupials based on x-ray computed tomography. B Am Mus Nat Hist. 2012:365:1-91.

36. Beck RMD, Travouillon KJ, Aplin KP, Godthelp H, Archer M. The osteology and systematics of the enigmatic Australian Oligo-Miocene metatherian Yalkaparidon (Yalkaparidontidae; Yalkaparidontia;? Australidelphia; Marsupialia). J Mamm Evol. 2014;21:127-72.

37. Beck RMD. The skull of Epidolops ameghinoi from the Early Eocene Itabora fauna, Southeastern Brazil, and the affinities of the extinct marsupialiform order Polydolopimorphia. J Mamm Evol. 2016. doi:10.1007/s10914-016-9357-6.

38. Voss RS, Jansa SA. Phylogenetic relationships and classification of didelphid marsupials, an extant radiation of New World metatherian mammals. B Am Mus Nat Hist. 2009:322:1-177.

39. Smith KK. Craniofacial development in marsupial mammals: developmental origins of evolutionary change. Dev Dynam. 2006;235:1181-93.

40. Tyndale-Biscoe H. Life of marsupials. Melbourne: CSIRO Publishing; 2005.

41. Maier W. Der Processus angularis bei Monodelphis domestica (Didelphidae; Marsupialia) und seine Beziehungen zum Mittelohr: Eine ontogenetische und evolutionsmorphologische Untersuchung. Gegenbaurs Morphol Jahrb. 1987;133:123-61.
42. Maier W. Cranial morphology of the therian common ancestor, as suggested by the adaptations of neonate marsupials. In: Szalay FS, Novacek MJ, McKenna MC, editors. Mammal phylogeny Mesozoic differentiation, multituberculates, monotremes, early therians and marsupials. New York: Springer; 1993. p. 165-81.

43. Goswami A, Randau M, Polly PD, Weisbecker V, Bennett CV, Hautier L, SánchezVillagra MR. Do developmental constraints and high integration limit the evolution of the marsupial oral apparatus? Integr Comp Biol. 2016;56:404-15.

44. Koyabu D, Werneburg I, Morimoto N, Zollikofer CPE, Forasiepi AM, Endo H, Kimura J, Ohdachi SD, Son NT, Sánchez-Villagra MR. Mammalian skull heterochrony reveals modular evolution and a link between cranial development and brain size. Nat Commun. 2014;5:3625.

45. Kuhn H-J. Die Entwicklung und Morphologie des Schädels von Tachyglossus aculeatus. Abh Senckenb Nat Gesell. 1971;528:1-224.

46. Padian K, Lamm E-T. Bone histology of fossil tetrapods: advancing methods, analysis, and interpretation. Berkeley: University of California Press; 2013.

47. Starck D. Embryologie: Ein Lehrbuch auf allgemein biologischer Grundlage. Stuttgart: Georg Thieme; 1955.

48. Sánchez-Villagra MR. Ontogenetic and phylogenetic transformations of the vomeronasal complex and nasal floor elements in marsupial mammals. Zool J Linn Soc. 2001:131:459-79.

49. Broom R. On the comparative anatomy of the organ of Jacobson in the marsupials. P Linn Soc N S W. 1896;21:591-623.

50. Broom R. A contribution to the comparative anatomy of the mammalian organ of Jacobson. T Roy Soc Edin-Earth. 1897;39:231-51.

51. Broom R. Observations on the development of the marsupial skull. P Linn Soc N S W. 1909;34:195-214

52. Broom R. On the mammalian presphenoid and mesethmoid bones. P Zool Soc Lond. 1926;96:257-64.

53. Toeplitz C. Bau und Entwicklung des Knorpelschädels von Didelphys marsupialis. Zoologica. 1920;27:1-83.

54. Denison W, Terry RJ. The chondrocranium of Caluromys. Wash Univ Stud. 1921;8:161-82.

55. Cords E. Über das Primordialcranium von Perameles spec.? Unter Berücksichtigung der Deckknochen. Anatomische Hefte. 1915;1(52):1-84

56. Esdaile PC. On the structure and development of the skull and laryngeal cartilages of Perameles, with notes on cranial nerves. Philos T R Soc Lon B. 1916:215:119-49.

57. Maier $\mathbf{W}$. The ontogenetic development of the orbitotemporal region in the skull of Monodelphis domestica (Didelphidae, Marsupialia), and the problem of the mammalian alisphenoid. In: Kuhn $\mathrm{H}-J$, Zeller $\mathrm{U}$, editors. Morphogenesis of the mammalian skull. Hamburg: Mammalia Depicta. Verlag Paul Parey; 1987. p. 71-90.

58. Maier W. Ala temporalis and alisphenoid in therian mammals. In: Splechtna $\mathrm{H}$, Hilgers $\mathrm{H}$, editors. Trends in vertebrate morphology. Stuttgart: Fischer; 1989. p. 396-400.

59. Maier W. Phylogeny and ontogeny of mammalian middle ear structures. Neth J Zool. 1990;40:55-74.

60. Klutzny S. Das Chondocranium von Vombatus ursinus (Shaw, 1800) bei einer Kopflänge von $14 \mathrm{~mm}$ und Scheitel-Steiß-Länge von $31.5 \mathrm{~mm}$ [Diplomarbeit]. Tübingen: Universität Tübingen; 1994.

61. Müller U. Zur Morphogenese der Ethmoidal- und Orbitotemporalregion bei Wallabia rufogrisea (Marsupialia) [Doktorgrades der Medizin]. Frankfurt am Main: Johann Wolfgang Goethe-Universität; 1986.

62. Schmelzle T. Ontogenetische Untersuchungen an der Ohrregion von Macropus eugenii (DESMAREST, 1817) (Macropodidae; Marsupialia) [Diploma Thesis]. Tübingen: Eberhard-Karls-Universität Tübingen; 2003.

63. Clark CT, Smith KK. Cranial osteogenesis in Monodelphis domestica (Didelphidae) and Macropus eugenii (Macropodidae). J Morphol. 1993;215:119-49.

64. Smith KK. Development of craniofacial musculature in Monodelphis domestica (Marsupialia, Didelphidae). J Morphol. 1994;222:149-73.

65. Sánchez-Villagra MR. Patterns of morphological change in the ontogeny and phylogeny of the marsupial skull [Ph.D. thesis]. Durham: Duke University; 1998.

66. Aplin K. Basicranial regions of diprotodontian marsupials: anatomy, ontogeny and phylogeny [Ph.D. thesis]. Sydney: University of New South Wales; 1990

67. Wible JR. Petrosals of Late Cretaceous marsupials from North America, and a cladistic analysis of the petrosal in therian mammals. J Vertebr Paleontol. 1990;10:183-205.

68. Wible JR, Hopson JA. Homologies of the prootic canal in mammals and non-mammalian cynodonts. J Vertebr Paleontol. 1995;15:331-56. 
69. Parker WK. On the structure and development of the skull in the Mammalia. Part II. Edentata. Philos T R Soc Lon B. 1885;176:1-119.

70. Roux $\mathrm{GH}$. The cranial development of certain Ethiopian "Insectivores" and its bearing on the mutual affinities of the group. Acta Zool. 1947;28:165-397.

71. Starck D. Le crâne des mammifères. In: Grasse PP, editor. Traité de Zoologie. 1967. p. 405-549.

72. Zeller U. Morphogenesis of the mammalian skull with special reference to Tupaia. In: Kuhn HJ, Zeller U, editors. Morphogenesis of the mammalian skull. Hamburg: Verlag Paul Parley; 1987. p. 17-50.

73. Moore WJ. The Mammalian Skull. Cambridge: Cambridge University Press; 1981.

74. Novacek MJ. Patterns of diversity in the mammalian skull. In: Hanken J, Hall BK, editors. The Skull. Chicago: The University of Chicago Press; 1993. p. 438-545.

75. Maier W. On the evolutionary biology of early mammals - with methodological remarks on the interaction between ontogenetic adaptation and phylogenetic transformation. Zool Anz. 1999;238:55-74.

76. Presley R, Steel FLD. On the homology of the alisphenoid. J Anat. 1976;121: 441-59.

77. Presley R, Steel FLD. The pterygoid and ectopterygoid in mammals. Anat Embryol. 1978;154:95-110.

78. Presley R. Alisphenoid equivalent in placentals, marsupials, monotremes, and fossils. Nature. 1981;294:668-70.

79. Abdala F, Giannini NP. Gomphodont cynodonts of the Chañares Formation: the analysis of an ontogenetic sequence. J Vertebr Paleontol. 2000;20:501-6.

80. Flores DA, Abdala F, Martin GM, Giannini NP, Martinez JM. Post-weaning cranial growth in shrew opossums (Caenolestidae): a comparison with bandicoots (Peramelidae) and carnivorous marsupials. J Mamm Evol. 2015; 22:285-303.

81. Wilson LAB. Comparison of prenatal and postnatal ontogeny: cranial allometry in the African striped mouse (Rhabdomys pumilio). J Mammal. 2011;92:407-20.

82. Young NM, Hu D, Lainoff AJ, Smith FJ, Diaz R, Tucker AS, Trainor PA, Schneider RA, Hallgrímsson B, Marcucio RS. Embryonic bauplans and the developmental origins of facial diversity and constraint. Development. 2014; 141:1059-63.

83. Smith FJ, Percival CJ, Young NM, Hu D, Schneider RA, Marcucio RS, Hallgrimsson B. Divergence of craniofacial developmental trajectories among avian embryos. Dev Dyn. 2015;244:1158-67.

84. Werneburg I, Tzika AC, Hautier L, Asher RJ, Milinkovitch MC, Sánchez-Villagra MR. Development and embryonic staging in non-model organisms: the case of an afrotherian mammal. J Anat. 2013;222:2-18.

85. Werneburg I, Laurin M, Koyabu D, Sánchez-Villagra MR. Evolution of organogenesis and the origin of altriciality in mammals. Evol Dev. 2016;18:229-44.

86. Beard J. The birth-period of Trichosurus vulpecula: Frommannsche Buchdruckerei (Hermann Pohle). 1897.

87. Bininda-Emonds ORP, Jeffrey JE, Richardson MK. Is sequence heterochrony an important evolutionary mechanism in mammals? J Mamm Evol. 2003;10: 335-61.

88. Werneburg I. A standard system to study vertebrate embryos. PLoS One. 2009;4:e5887.

89. Giere P, Freyer C, Zeller U. Opening of the mammalian vomeronasal organ with respect to the Glires hypothesis: a cladistic reconstruction of the therian morphotype. Zoosyst Evol. 1999;75:247-55.

90. Stößel A, Junold A, Fischer MS. The morphology of the eutherian ethmoidal region and its implications for higher-order phylogeny. J Zool Syst Evol Res. 2010;48:167-80.

91. Koyabu D, Maier W, Sánchez-Villagra MR. Paleontological and developmental evidence resolve the homology and dual embryonic origin of a mammalian skull bone, the interparietal. Proc Natl Acad Sci. 2012;109:14075-80.

92. Wible JR, Rougier GW. Cranial anatomy of Kryptobaatar dashzevegi (Mammalia, Multituberculata), and its bearing on the evolution of mammalian characters. B Am Mus Nat Hist. 2000;247:1-120.

93. Mead JG, Fordyce RE. The therian skull: a lexicon with emphasis on the odontocetes. Smithson Contr Zool. 2009:1-248.

94. Freyer C. Die Regio ethmoidalis in der Ontogenese von Monodelphis domestica (Didelphidae: Marsupialia): Ein Beitrag zur Rekonstruktion des Grundplanes der Marsupialia [Diplomarbeit]. Berlin: Humboldt - Universität zu Berlin; 1999.

95. Rowe TB, Eiting TP, Macrini TE, Ketcham RA. Organization of the olfactory and respiratory skeleton in the nose of the gray short-tailed opossum Monodelphis domestica. J Mamm Evol. 2005;12:303-36.
96. Kuratani S, Adachi N, Wada N, Oisi Y, Sugahara F. Developmental and evolutionary significance of the mandibular arch and prechordal/ premandibular cranium in vertebrates: revising the heterotopy scenario of gnathostome jaw evolution. J Anat. 2013;222:41-55.

97. McBratney-Owen B, Iseki S, Bamforth SD, Olsen BR, Morriss-Kay GM. Development and tissue origins of the mammalian cranial base. Dev Biol. 2008;322:121-32.

98. Sánchez-Villagra MR, Wible JR. Patterns of evolutionary transformation in the petrosal bone and some basicranial features in marsupial mammals, with special reference to didelphids. J Zool Syst Evol Res. 2002;40:26-45.

99. Gaudin TJ, Wible JR, Hopson JA, Turnbull WD. Reexamination of the morphological evidence for the Cohort Epitheria (Mammalia, Eutheria). J Mamm Evol. 1996;3:31-79.

100. Voss RS, Jansa SA. Phylogenetic studies on didelphid marsupials II. Nonmolecular data and new IRBP sequences: separate and combined analyses of didelphine relationships with denser taxon sampling. B Am Mus Nat Hist. 2003:1-82.

101. Muizon C de. Mayulestes ferox, a borhyaenoid (Metatheria, Mammalia) from the early Palaeocene of Bolivia. Phylogenetic and palaeobiologic implications. Geodiversitas. 1998;20:19-142.

102. Horovitz I, Sánchez-Villagra MR. A morphological analysis ocbrsf marsupial mammal higher-level phylogenetic relationships. Cladistics. 2003;19:181-212.

103. Forasiepi AM. Osteology of Arctodictis sinclairi (Mammalia, Metatheria, Sparassodonta) and phylogeny of Cenozoic metatherian carnivores from South America. Monografías del Museo Argentino de Ciencias Naturales. 2009:6:1-174.

104. Broom R. On the organ of Jacobson and some other structures in the nose of Caenolestes. P Zool Soc Lond. 1926;1926:419-24.

105. Van Valkenburgh B, Smith T, Craven B, Laitman JT. Special issue: The vertebrate nose: evolution, structure, and function. Anat Rec. 2014;297: 1971-2226.

106. Hennig W. Phylogenetic systematics. Urbana: University of Illinois Press; 1966.

107. Kratzing JE. The anatomy and histology of the nasal cavity of the koala (Phascolarctos cinereus). J Anat. 1984;138:55-65.

108. Ade M. External morphology and evolution of the rhinarium of Lagomorpha. With special reference to the Glires hypothesis. Zoosyst Evol. 1999;75:191-216.

109. Jones TE, Munger BL. Early differentiation of the afferent nervous system in glabrous snout skin of the opossum (Monodelphis domesticus). Somatosens Res. 1985;3:169-84.

110. Hughes RL, Hall LS. Structural adaptations of the newborn marsupial. In: Tyndale-Biscoe $\mathrm{CH}$, Janssens PA, editors. The developing marsupial. Berlin, Heidelberg: Springer Verlag; 1988. p. 8-27.

111. Gemmell RT, Rose RW. The senses involved in movement of some newborn Macropodoidea and other marsupials from cloaca to pouch. In: Grigg G, Jarman P, Hume I, editors. Kangaroos, Wallabies and Rat-Kangaroos. Chipping Norton: Surrey Beatty \& Sons Pty Limited; 1989. p. 339-47.

112. Krause WJ. A scanning electron microscopic study of the opossum nasal cavity prior to and shortly after birth. Anat Embryol. 1992;185:281-9.

113. Morrison KM, Miesegaes GR, Lumpkin EA, Maricich SM. Mammalian Merkel cells are descended from the epidermal lineage. Dev Biol. 2009;336:76-83.

114. Schneider NY. The development of the olfactory organs in newly hatched monotremes and neonate marsupials. J Anat. 2011;219:229-42.

115. Elsner M. Ontogenie und Funktionsmorphologie des Kopfes bei physiologischer Frühgeburt: Untersuchungen an Monodelphis domestica [Inaugural - Dissertation]. Göttingen: Universität Göttingen; 1995.

116. Maier W. Morphology of the interorbital region of Saimiri sciureus. Folia Primatol. 1983;41:277-303.

117. Ichishima H. Do cetaceans have the mesethmoid. Mem Fukui Pref Dinosaur Mus. 2011;10:63-75 (In Japanese).

118. Ichishima H. The ethmoid and presphenoid of cetaceans. J Morphol. 2016. doi:10.1002/jmor.20615.

119. Ferigolo J. The mesethmoid bone and the Edentata. An Acad Bras Cienc. 1981;53:817-24

120. Sánchez-Villagra MR, Goswami A, Weisbecker V, Mock O, Kuratani S. Conserved relative timing of cranial ossification patterns in early mammalian evolution. Evol Dev. 2008;10:519-30.

121. Martinelli AG, Rougier GW. On Chaliminia musteloides (Eucynodontia: Tritheledontidae) from the Late Triassic of Argentina, and a phylogeny of Ictidosauria. J Vertebr Paleontol. 2007;27:442-60.

122. Kemp TS. The endocranial cavity of a nonmammalian eucynodont, Chiniquodon theotenicus, and its implications for the origin of the mammalian brain. J Vertebr Paleontol. 2009;29:1188-98. 
123. Crompton AW, Musinsky C, Owerkowicz T. Evolution of the mammalian nose. In: Dial KP, Shubin N, Brainerd EL, editors. Great transformations in vertebrate evolution. Chicago and London: University of Chicago Press; 2015. p. 424.

124. Reinbach W. Über einen Rest des Parasphenoids bei einem rezenten Säugetier. Z Morphol Anthropol. 1952:43:195-205.

125. Atkins JB, Franz-Odendaal TA. The evolutionary and morphological history of the parasphenoid bone in vertebrates. Acta Zool. 2016;97:255-63.

126. Kuhn $\mathrm{H}-J$, Zeller $\mathrm{U}$. The Cavum epiptericum in monotremes and therian mammals. In: Kuhn H-J, Zeller U, editors. Morphogenesis of the mammalian skull. Hamburg: Mammalia Depicta. Verlag Paul Parey; 1987. p. 51-70.

127. Wible JR. On the cranial osteology of the Hispaniolan solenodon, Solenodon paradoxus Brandt, 1833 (Mammalia, Lipotyphla, Solenodontidae). Ann Carnegie Mus. 2008;77:321-402.

128. Hopson JA, Rougier GW. Braincase structure in the oldest known skull of a therian mammal: Implications for mammalian systematics and cranial evolution. Am J Sci. 1993;293-A:268-99.

129. Novacek MJ. The skull of leptictid insectivorans and the higher-level classification of eutherian mammals. B Am Mus Nat Hist. 1986;183:1-112.

130. Ashwell KWS. Neurobiology of monotremes: brain evolution in our distant mammalian cousins. Collingwood: CSIRO Publishing; 2013. p. 522.

131. Anthwal N, Thompson $\mathrm{H}$. The development of the mammalian outer and middle ear. J Anat. 2016;228:217-32

132. Luo Z-X. Developmental patterns in Mesozoic evolution of mammal ears. Annu Rev Ecol Evol. 2011:42:355-80.

133. Crompton AW. The evolution of the jaw articulation of cynodonts. Studies in vertebrate evolution. Edinburgh: Oliver and Boyd; 1972. p. 231-51.

134. Kermack KA, Mussett F, Rigney HW. The lower jaw of Morganucodon. Zool J Linn Soc. 1973;53:87-175.

135. Allin EF. Evolution of the mammalian middle ear. J Morphol. 1975;147:403-38

136. Kemp TS. The origin and evolution of mammals. Oxford: Oxford University Press; 2005.

137. Meng J, Bi S, Zheng X, Wang X. Ear ossicle morphology of the Jurassic euharamiyidan Arboroharamiya and evolution of mammalian middle ear. J Morphol. 2016

138. Filan SL. Development of the middle ear region in Monodelphis domestica (Marsupialia, Didelphidae): marsupial solutions to an early birth. J Zool. 1991;225:577-88.

139. Maier W, Ruf I. Evolution of the mammalian middle ear: a historical review. J Anat. 2016:228:270-83.

140. Allin EF, Hopson JA. Evolution of the auditory system in Synapsida ("mammal-like reptiles" and primitive mammals) as seen in the fossil record. In: Webster DB, Fay RR, Popper AN, editors. The Evolutionary Biology of Hearing. New York: Springer; 1992. p. 587-614.

141. Ramírez-Chaves HE, Wroe SW, Selwood L, Hinds LA, Leigh C, Koyabu D, Kardjilov N, Weisbecker V. Mammalian development does not recapitulate suspected key transformations in the evolutionary detachment of the mammalian middle ear. Proc R Soc B. 2016;283:20152606.

142. Smith KK, van Nievelt AFH. Comparative rates of development in Monodelphis and Didelphis. Science. 1997;275:683-4.

143. Ji Q, Luo Z-X, Yuan C-X, Wible JR, Zhang J-P, Georgi JA. The earliest known eutherian mammal. Nature. 2002;416:816-22.

144. Wang Y, Hu Y, Meng J, Li C. An ossified Meckel's cartilage in two Cretaceous mammals and origin of the mammalian middle ear. Science. 2001;294:357-61.

145. Sánchez-Villagra MR, Gemballa S, Nummela S, Smith KK, Maier W. Ontogenetic and phylogenetic transformations of the ear ossicles in marsupial mammals. J Morphol. 2002;251:219-38.

146. Weil R. Development of the ossicula audita in the opossum. Ann Ny Acad Sci. 1899;12:103-12.

147. McCrady E. The embryology of the opossum. Amer Anat Mem. 1938;16:1-233.

148. Takechi M, Kuratani S. History of studies on mammalian middle ear evolution: a comparative morphological and developmental biology perspective. J Exp Zool Part B. 2010;314:417-33.

149. Voit M. Über einige neuere Ergebnisse am Primordialcranium der Säugetiere. Verh der anatomischen Gesellschaft Gießen. 1909;23:139-47.

150. Hyrtl J. Lehrbuch der Anatomie des Menschen. 12. Auflage ed. Vienna: Braumüller; 1873

151. Rougier GW, Wible JR, Hopson JA. Reconstruction of the cranial vessels in the early Cretaceous mammal Vincelestes neuquenianus: Implications for the evolution of the mammalian cranial vascular system. J Vertebr Paleontol. $1992 ; 12: 188-216$.
152. Norris CA. The periotic bones of possums and cuscuses: cuscus polyphyly and the division of the marsupial family Phalangeridae. Zool J Linn Soc. 1994;111:73-98.

153. Cartmill M. Anatomy, antinomies, and the problem of anthropoid origins. In: Fleagle JG, Kay RF, editors. Anthropoid Origins. New York: Plenum Press; 1994. p. 549-66.

154. Segall W. The middle ear region of Dromiciops. Acta Anat. 1969;72:489-501.

155. Segall W. The auditory ossicles (malleus, incus) and their relationships to the tympanic: in marsupials. Acta Anat. 1969;73:176-91.

156. Segall W. Morphological parallelisms of the bulla and auditory ossicles in some insectivores and marsupials. Fieldiana Zool. 1970;51:169-205.

157. Marshall LG. Evolution of metatherian and eutherian (mammalian) characters: a review based on cladistic methodology. Zool J Linn Soc. 1979;66:369-410.

158. Reig OA, Kirsch JAW, Marshall LG. Systematic relationships of the living and the neocenozoic american "oposum-like" marsupials (Suborder Didelphiomorphia), with comments on the classification of these and of the Cretaceous and Paleogene New World and European metatherians. In: Archer M, editor. Possums and Opossums: Studies in Evolution. Sydney: Surrey Beatty \& Sons and the Royal Zoological Society of New South Wales; 1987. p. 1-89.

159. Muizon C de. A new carnivorous marsupial from the Palaeocene of Bolivia and the problem of marsupial monophyly. Nature. 1994;370:208-11.

160. Marshall LG, Muizon C de. Part II: The Skull. In: Muizon C de, editor. Pucadelphys andinus (Marsupialia, Mammalia) from the early Paleocene of Bolivia. Paris: Mémoires du Museum National d'Histoire Naturelle; 1995. p. 21-90.

161. Muizon C de, Cifelli RL, Paz CR. The origin of the dog-like borhyaenoid marsupials of South America. Nature. 1997;370:486-9.

162. Horovitz I, Ladevèze S, Argot C, Macrini Thomas E, Hooker JJ, Kurz C, De Muizon C, Sánchez-Villagra MR. The anatomy of Herpetotherium cf. fugax Cope, 1873, a metatherian from the Oligocene of North America. Palaeontographica. 2008;284:109-41.

163. Szalay FS, Trofimov BA. The Mongolian Late Cretaceous Asiatherium, and the early phylogeny and paleobiogeography of Metatheria. J Vertebr Paleontol. 1996;16:474-509.

164. Novacek MJ, Wyss AR, McKenna MC. The major groups of eutherian mammals. In: Benton MJ, editor. The Phylogeny and Classification of the Tetrapods, vol 2 Mammals. Oxford: Clarendon; 1988. p. 31-71.

165. Keyte AL, Smith KK. Opossum (Monodelphis domestica): a marsupial development model. Cold Spring Harbor Protocols. Cold Spring Harbor: Cold Spring Harbor Laboratory Press; 2008. p. pdb. emo104.

166. MacPhee RDE. Ectotympanics, ontogeny, and primates. Folia Primatol. 1979;31:23-47.

167. Fischer MS. Zur Ontogenese der Tympanalregion der Procaviidae (Mammalia: Hyracoidea). Gegenbaurs Morphol Jahrb. 1989;135:795-840.

168. MacPhee RDE, Novacek MJ. Definition and relationships of Lipotyphla. In: Szalay FS, Novacek MJ, McKenna MC, editors. Mammal phylogeny Placentals. New York: Springer; 1993. p. 13-31.

169. van der Klaauw CJ. Über die Entwickelung des Entotympanicums. d Ned Dierk Ver. 1922;2:135-76

170. Schneider R. Zur Entwicklung des Chondrocraniums der Gattung Bradypus. Morphol Jahrb. 1955;95:79-141.

171. Spatz WB. Zur Ontogenese der Bulla tympanica von Tupaia glis Diard 1820 (Prosimiae, Tupaiiformes). Folia Primatol. 1966;4:26-50.

172. Novacek MJ. Aspects of the problem of variation, origin and evolution of the eutherian auditory bulla. Mammal Rev. 1977;7:131-49.

173. Presley R. Development and the phylogenetic features of the middle ear region. In: Szalay FS, Novacek MJ, McKenna MC, editors. Mammal Phylogeny Mesozoic Differentiation Multituberculates, Monotremes, Early Therians and Marsupials. New York: Springer; 1993. p. 21-9.

174. Maier W. The entotympanic in late fetal Artiodactyla (Mammalia). J Morphol. 2013;274:926-39.

175. Fawcett E. The primordial cranium of Erinaceus europaeus. J Anat. 1918;52: 211-50.

176. Carlsson A. Über den Bau des Dasyuroides byrnei und seine Beziehungen zu den übrigen Dasyuridae. Acta Zool-Stockholm. 1926;7:249-75.

177. Wood-Jones F. The study of a generalized marsupial (Dasycercus cristicauda Krefft). Trans Zool Soc London. 1949;26(5):408-501.

178. Segall W. The auditory region (ossicles, sinuses): in gliding mammals and selected representatives of non-gliding genera. Fieldiana Zool. 1971:58:27-59.

179. Hershkovitz P. Ankle bones: the chilean opossum Dromiciops gliroides Thomas, and marsupial phylogeny. Bonner Zoologische Beiträge. 1992:43: $181-213$. 
180. Patterson B. The auditory region of the borhyaenid marsupial Cladosictis. 1965. p. 1-9.

181. Presley R. Ontogeny of some elements of the auditory bulla in mammals. J Anat. 1978;126:428

182. Presley R. The braincase of recent and mesozoic therapsids. Memoir de la Societé géologique Française (NS). 1980;139:159-62.

183. Norris CA. Changes in the composition of the auditory bulla in southern Solomon Islands populations of the grey cuscus, Phalanger orientalis breviceps (Marsupialia, Phalangeridae). Zool J Linnean Soc. 1993;107:93-106.

184. Wible JR, Martin JR. Ontogeny of the tympanic floor and roof in archontans. In: MacPhee RDE, editor. Primates and their relatives in phylogenetic perspective. New York: Plenum Press; 1993. p. 111-48.

185. Reig OA, Simpson GG. Sparassocynus (Marsupialia, Didelphidae), a peculiar mammal from the Late Cenozoic of Argentina. J Zool. 1972;167:511-39.

186. Schoenwolf GC, Bleyl SB, Brauer PR, Francis-West PH. Larsen's human embryology. 5th ed. London: Churchill Livingstone; 2014.

187. Maier W, van den Heever J, Durand F. New therapsid specimens and the origin of the secondary hard and soft palate of mammals. J Zool Syst Evol Res. 1996;34:9-19.

188. Weber M. Die Säugetiere. Jena: Fischer; 1928.

189. Edgeworth FH. The cranial muscles of vertebrates. Cambridge: Cambridge University Press; 1935.

190. Sucheston ME, Cannon MS. Eustachian tube of several mammalian species. Archiv Otolaryngol. 1971;93:58-64.

191. Ross MH, Romrell L, Kaye Gl. Histology. 3rd ed. Baltimore: Williams and Wilkins; 1995.

192. Kummer B. Kausale Histogenese der Gewebe des Bewegungsapparates und funktionelle Anpassung. In: Staubesand J, editor. Makroskopische und mikroskopische Anatomie des Menschen. München: Urban \& Schwarzenberg; 1985. p. 199-213.

193. Warwick R, Williams PL. Gray's Anatomy. 35th ed. Philadelphia: W. B. Saunders; 1973.

194. Proctor B. Embryology and anatomy of the eustachian tube. Arch Otolaryngol. 1967;86:51-62.

195. Ruf I, Maier W. Topography of the chorda tympani nerve and the tensor tympani muscle in carnivores provides a new synapomorphy for Herpestidae (Carnivora, Mammalia). J Morphol. 2010;271:612-20.

196. Haas A. Phylogeny of frogs as inferred from primarily larval characters (Amphibia: Anura). Cladistics. 2003;19:23-89.

197. Catalano SA, Goloboff PA, Giannini NP. Phylogenetic morphometrics (I): the use of landmark data in a phylogenetic framework. Cladistics. 2010;26:539-49.

198. Paluh DJ, Sheil CA. Anatomy of the fully formed chondrocranium of Emydura subglobosa (Chelidae): a pleurodiran turtle. J Morphol. 2013;274:1-10.

199. Sheil CA, Zaharewicz K. Anatomy of the fully formed chondrocranium of Podocnemis unifilis (Pleurodira: Podocnemididae). Acta Zool-Stockholm. 2014;95:358-66.

200. Hirasawa T, Oisi Y, Kuratani S. Palaeospondylus as a primitive hagfish Zoological Letters. 2016;2:20.

201. Guillerme T, Cooper N. Assessment of available anatomical characters for linking living mammals to fossil taxa in phylogenetic analyses. Biol Letters. 2016;12:20151003.

202. Asher RJ, Bennett N, Lehmann T. The new framework for understanding placental mammal evolution. Bioessays. 2009:31:853-64.

203. Martin T, Ruf I. On the mammalian ear. Science. 2009;326:243-4.

204. Werneburg I. The cranial musculature of turtles. Palaeontol Electron. 2011;14:1-99.

205. Luckett WP. An ontogenetic assessment of dental homologies in therian mammals. In: Szalay FS, Novacek MJ, McKenna MC, editors. Mammal phylogeny Mesozoic differentiation, multituberculates, monotremes, early therians and marsupials. New York: Springer; 1993. p. 182-204.

206. van Nievelt AFH, Smith KK. Tooth eruption in Monodelphis domestica and its significance for phylogeny and natural history. J Mammal. 2005;86:333-41.

207. van Nievelt AFH, Smith KK. To replace or not to replace: the significance of reduced functional tooth replacement in marsupial and placental mammals. Paleobiology. 2005;31:324-46.

208. Fuchs H. Über den Bau und die Entwicklung des Schädels der Chelone imbricata. Ein Beitrag zur Entwicklungsgeschichte und vergleichenden Anatomie des Wirbeltierschädels. Erster Teil: Das Primordialskelett des Neurocraniums und des Kieferbogens. In: Voeltzkow A, editor. Reise in Ostafrika in den Jahren 1903-1905, wissenschaftliche Ergebnisse. Stuttgart: Schweizerbart'sche Verlagsbuchhandlung; 1915. p. 1-325.
209. Beer GR. Studies on the vertebrate head. II. The orbito-temporal region of the skull. 1926;70:263-370.

210. Goodrich ES. Studies on the Structure and Development of Vertebrates. London: Macmillan; 1930.

211. Meredith RW, Westerman M, Springer MS. A phylogeny of Diprotodontia (Marsupialia) based on sequences for five nuclear genes. Mol Phylogenet Evol. 2009;51:554-71.

212. Westerman M, Krajewski C, Kear BP, Meehan L, Meredith RW, Emerling CA, Springer MS. Phylogenetic relationships of dasyuromorphian marsupials revisited. Zool J Linn Soc. 2016;176:686-701.

213. Gallus S, Janke A, Kumar V, Nilsson MA. Disentangling the relationship of the Australian marsupial orders using retrotransposon and evolutionary network analyses. Genome Biol Evol. 2015;7:985-92.

214. Beck RMD, Warburton NM, Archer M, Hand SJ, Aplin KP. Going underground: postcranial morphology of the early Miocene marsupial mole Naraboryctes philcreaseri and the evolution of fossoriality in notoryctemorphians. Memoirs of Museum Victoria. 2016;74:151-71.

215. Reinbach W. Zur Entwicklung des Primordialcraniums von Dasypus novemcinctus LINNE (Tatusia novemcincta LESSON). I Zeitschrift für Morphologie und Anthropologie. 1952;44:375-444.

216. Klima M. Morphogenesis of the nasal structures of the skull in toothed whales (Odontoceti). In: Kuhn H-J, Zeller U, editors. Morphogenesis of the Mammalian Skull. Hamburg: Mammalia Depicta. Verlag Paul Parey; 1987. p. 105-21.

\section{Submit your next manuscript to BioMed Central and we will help you at every step:}

- We accept pre-submission inquiries

- Our selector tool helps you to find the most relevant journal

- We provide round the clock customer support

- Convenient online submission

- Thorough peer review

- Inclusion in PubMed and all major indexing services

- Maximum visibility for your research

Submit your manuscript at www.biomedcentral.com/submit
C Biomed Central 